\title{
THE PENNSYLVANIA STATE UNIVERSITY
}

\author{
College of Engineering
}

FINAL REPORT

DE-FG07-99ID13778

Monitoring and Control Research Using a University Research Reactor and SBWR Test-Loop

\author{
Prepared by: \\ Professor Robert M. Edwards \\ 228 Reber Building \\ University Park, PA 16802 \\ rmenuc@engr.psu.edu \\ Submitted to \\ United States Department of Energy \\ Procurement Services Division \\ Idaho Operations Office \\ 850 Energy Drive \\ Idaho Falls, ID 83401-1563 \\ (208) 526-4169
}

September 28, 2003 


\section{Executive Summary}

The project was conducted over the four year period from July 1, 1999 to June 30, 2003. This interval incorporated a one year no-cost extension. Two $\mathrm{PhD}$ dissertations and two MS thesis projects resulted from this work. Other research publications numbered 30 and are listed in the project bibliography.

The existing hybrid simulation capability of the Penn State Breazeale nuclear reactor was expanded to conduct research for monitoring, operations and control. Hybrid simulation in this context refers to the use of the physical time response of the research reactor as an input signal to a real-time simulation of power-reactor thermal-hydraulics which in-turn provides a feedback signal to the reactor through positioning of an experimental changeable reactivity device (ECRD). An ECRD is an aluminum tube containing an absorber material that is positioned in the central thimble of the reactor by an external computer-driven algorithm. Simulation of parallel boiling channels and modal reactor kinetics were used to expand the hybrid reactor simulation (HRS) capability to include out-of-phase stability characteristics observed in operating BWRs.

The Penn State thermal-hydraulic test loop was constructed to mimic the boiling phenomena of a Simplified Boiling Water Reactor (SBWR), an advanced reactor design concept, in a unique atmospheric pressure facility where flow visualization is afforded by borosilicate glass piping. Electrically heated rods take the place of the nuclear reactor fuel. A hybrid loop simulation capability (HLS) was added to this facility where the physical thermal-hydraulic time response of the test-loop provides feedback to a reactor kinetics simulation whose power response generates a signal to drive the electrically heated rods.

Furthermore, the hardware and software protocols to electronically couple the research reactor and testloop (HRLS) were developed where the reactor response could provide a signal to drive the electrically heated rods in the testloop and the boiling response of the testloop could provide a feedback signal to position the ECRD in the research reactor.

The hybrid simulation capabilities represent innovative testing capabilities for advanced monitoring, operations, and control research, which often fail to consider the complexities associated with real physical processes, instrumentation, and computer implementation. The expansion of the facilities motivated research for optimized feedforward control, robust feedback control, on-line uncertainty monitoring, and BWR stability monitoring. 


\section{Table of Contents}

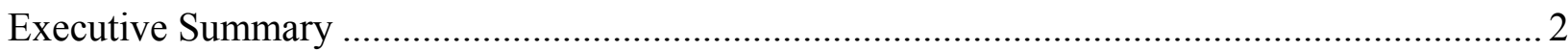

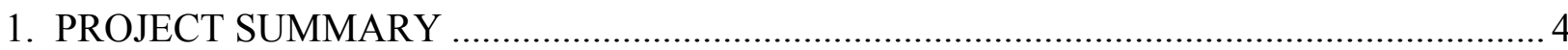

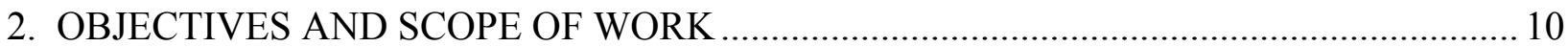

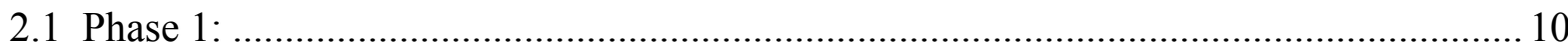

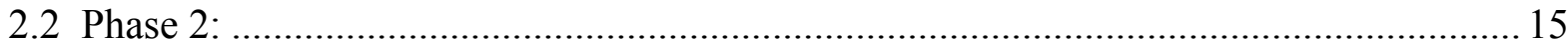

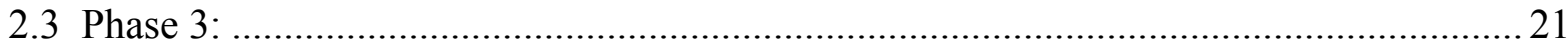

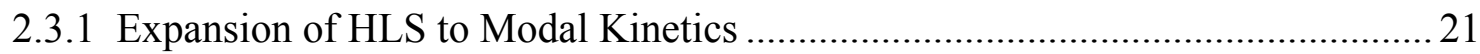

2.3.1.1 Low-Pressure Integral Test Facility (LPITF) ........................................ 23

2.3.1.2 Host Computer ................................................................................ 24

2.3.1.3 Target Computer ……………………………….............................. 26

2.3.1.4 Experimental Procedure And Results .................................................... 26

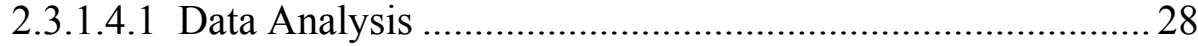

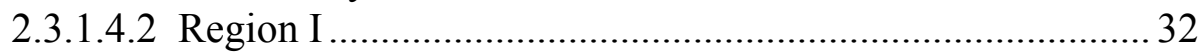

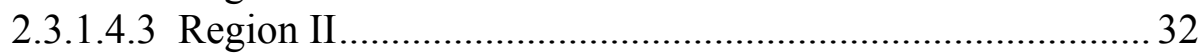

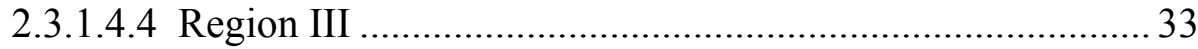

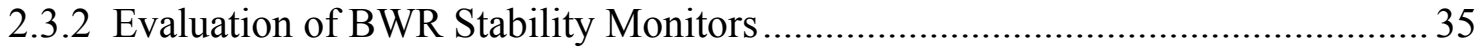

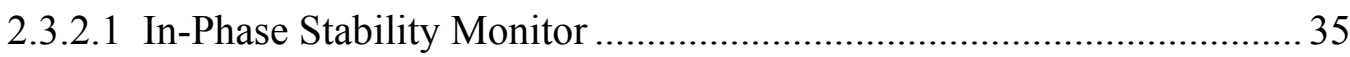

2.3.2.2 Out-of-Phase Stability Monitor ............................................................. 38

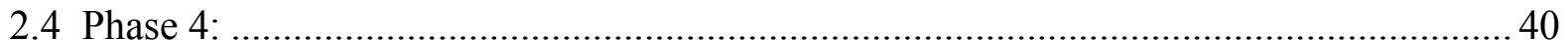

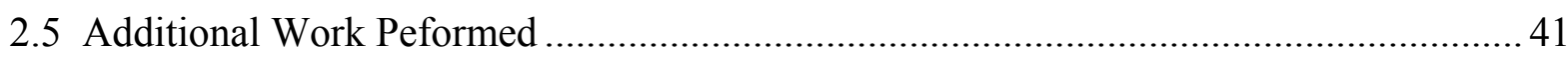

2.5.1 Thermal-Hydraulic Instabilities of Low Pressure Two-Phase Flow ..................... 41

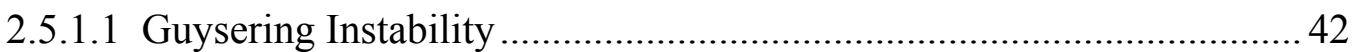

2.5.1.2 Instabilities induced by Void Flashing ……………............................. 45

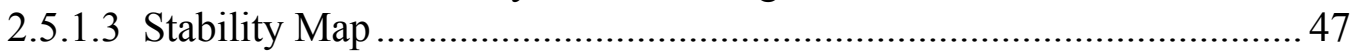

2.5.1.4 Dynamics of the Penn State Low-Pressure Integral Test Facility......... 50

2.5.2 Linear Stability Analysis .............................................................................. 51

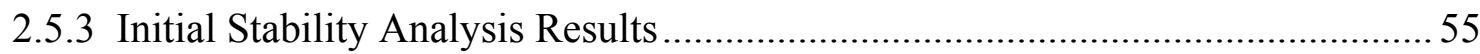

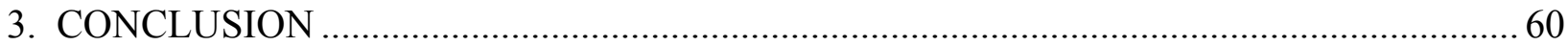

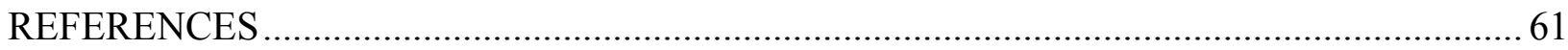

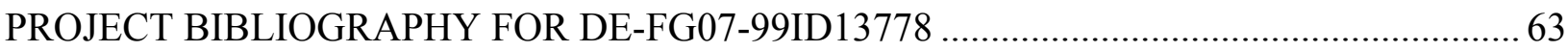

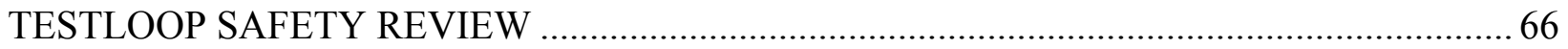




\section{PROJECT SUMMARY}

In previously completed research [1,2] the Penn State TRIGA reactor had been developed into a hybrid reactor simulator (HRS) where elementary thermal-hydraulic characteristics of commercial boiling water reactor (BWR) power plants is simulated in a digital computer. As shown in Figure 1, an ECRD is positioned by the simulation computer system, which is isolated from the licensed control and safety system. The ECRD is designed to operate within the Penn State TRIGA reactor technical specifications which define and allow a moveable experiment with up to a dollar's worth of reactivity and with positive reactivity insertion rates limited to less than 90 cents per second.[3] The simulated BWR reactivity feedback is used to drive the ECRD in the reactor, causing its observed power response to mimic stability phenomena actually encountered in BWR.

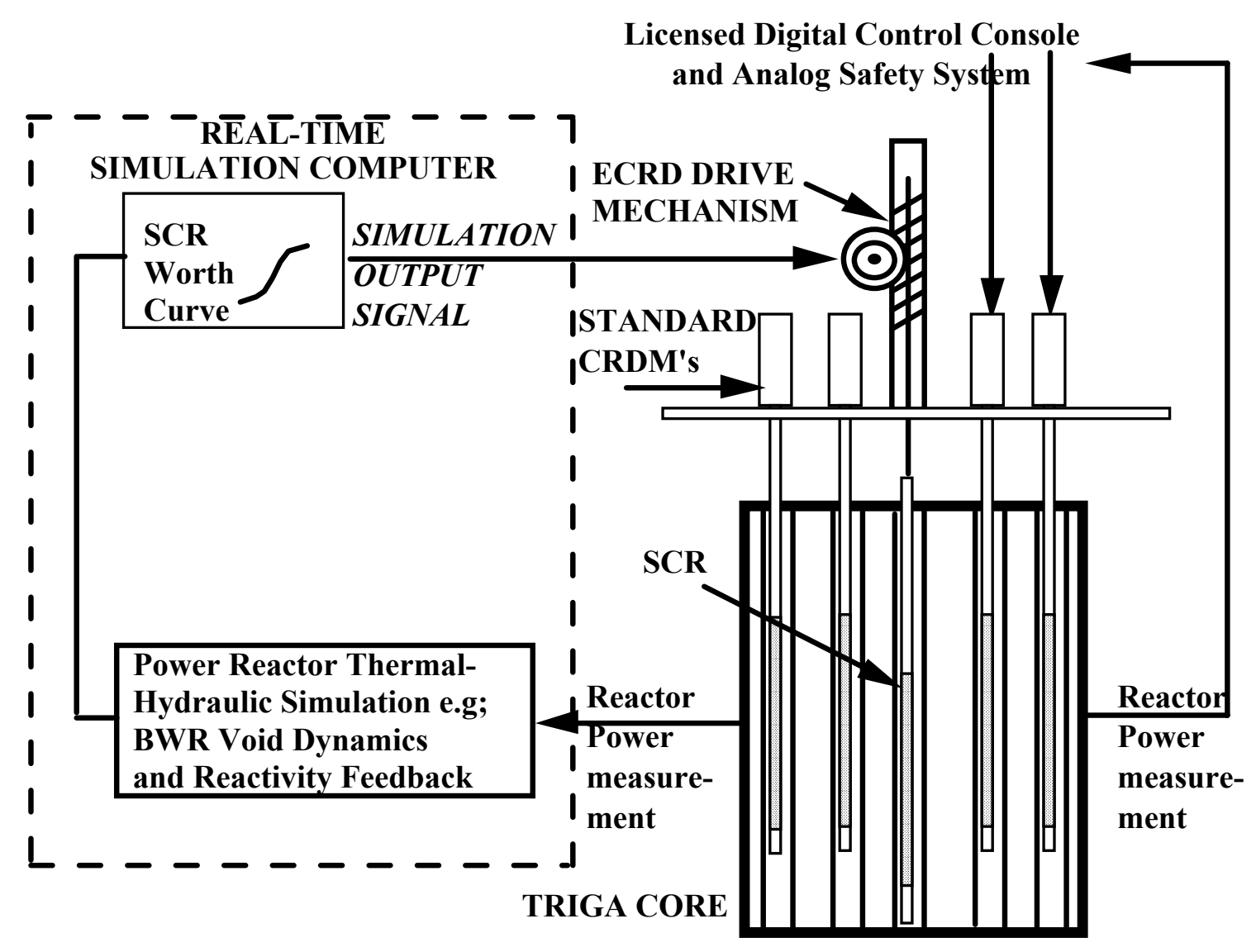

Figure 1. Hybrid Reactor Simulation (HRS) 
Using the LAPUR frequency domain code [4] low-order linear reactivity-feedback models were developed to match the experimentally determined external reactivity-to-power transfer functions. For example, a simplified model of the Vermont Yankee and Peach Bottom boiling water reactors is[5]:

$$
\begin{gathered}
\frac{d T(t)}{d t}=a_{1} n_{r}(t)-a_{2} T(t) \\
\frac{d^{2} \rho_{\alpha}(t)}{d t^{2}}+a_{3} \frac{d \rho_{\alpha}(t)}{d t}+a_{4} \rho_{\alpha}(t)=K T(t) \\
\rho(t)=\rho_{\alpha}(t)+\rho_{T_{f}}(t)+\rho_{\text {ext }}(t) \\
\rho_{T_{r}}(t)=D_{\text {T }}(t)
\end{gathered}
$$

The $a_{1}$ to $a_{4}$ coefficients of this reactivity feedback model are highly dependent on the overall core power and flow conditions. Nonetheless, elementary feedback models of this form were used to faithfully replicate BWR instability characteristics in the hybrid reactor simulator environment for the purpose of validating BWR stability monitoring techniques with realistic reactor power kinetics, noise and instrumentation.[1,2]

One objective of NEER project was to replace the linear feedback model approach with detailed thermal-hydraulic model of a boiling channel which represents the effects of the non-boiling, subcooled- boiling and bulk-boiling regions, axial-power profile, and recirculation flow rate.[6,7] The advantage of the more phenomenological approach is that it is less dependent on empirically developed coefficients and is applicable over a wider range of power and core flow conditions. Furthermore, out-of-phase instability characteristics were incorporated in the HRS by using a modalkinetics formulation $[6,8]$ and simulation of parallel boiling channels. The modal kinetics model is given as a set of four equations for the amplitudes of the fundamental mode $\mathrm{n}_{0}$ and the first harmonic $\mathrm{n}_{1}$ : 


$$
\begin{gathered}
\frac{\mathrm{dn}_{0}}{\mathrm{dt}}=\frac{\left(\rho_{0}^{\mathrm{s}}+\rho_{0}-\beta\right)}{\Lambda_{0}} \mathrm{n}_{0}+\frac{\rho_{1}}{\Lambda_{0}} \mathrm{n}_{1}+\sum_{\mathrm{i}=1}^{\mathrm{n}} \lambda_{\mathrm{i}} \mathrm{c}_{0 \mathrm{i}} \\
\frac{\mathrm{dc}_{0 \mathrm{i}}}{\mathrm{dt}}=\frac{\beta_{\mathrm{i}}}{\Lambda_{0}} \mathrm{n}_{0}-\lambda_{\mathrm{i}} \mathrm{c}_{0 \mathrm{i}} \\
\frac{\mathrm{dn}_{1}}{\mathrm{dt}}=\frac{\left(\rho_{1}^{\mathrm{s}}+\rho_{0}-\beta\right)}{\Lambda_{1}} \mathrm{n}_{1}+\frac{\rho_{1}}{\Lambda_{1}} \mathrm{n}_{0}+\sum_{\mathrm{i}=1}^{\mathrm{n}} \lambda_{\mathrm{i}} \mathrm{c}_{1 \mathrm{i}} \\
\frac{\mathrm{dc}_{1 \mathrm{i}}}{\mathrm{dt}}=\frac{\beta_{\mathrm{i}}}{\Lambda_{1}} \mathrm{n}_{1}-\lambda_{\mathrm{i}} \mathrm{c}_{1 \mathrm{i}}
\end{gathered}
$$

When combined with spatial distribution functions, the modal kinetics model represent the essential space and time dependent neutronic characteristics of observed BWR behavior where local channels fluctuate out-of-phase with core average or other channels:

$$
\Psi(\underline{r}, \mathrm{t})=\mathrm{n}_{0 \mathrm{r}}(\mathrm{t}) \phi_{0}(\underline{\mathrm{r}})+\mathrm{n}_{1 \mathrm{r}}(\mathrm{t}) \phi_{1}(\underline{\mathrm{r}})
$$

Examples of possible modal-model reactor-power response are shown in Figure 2.
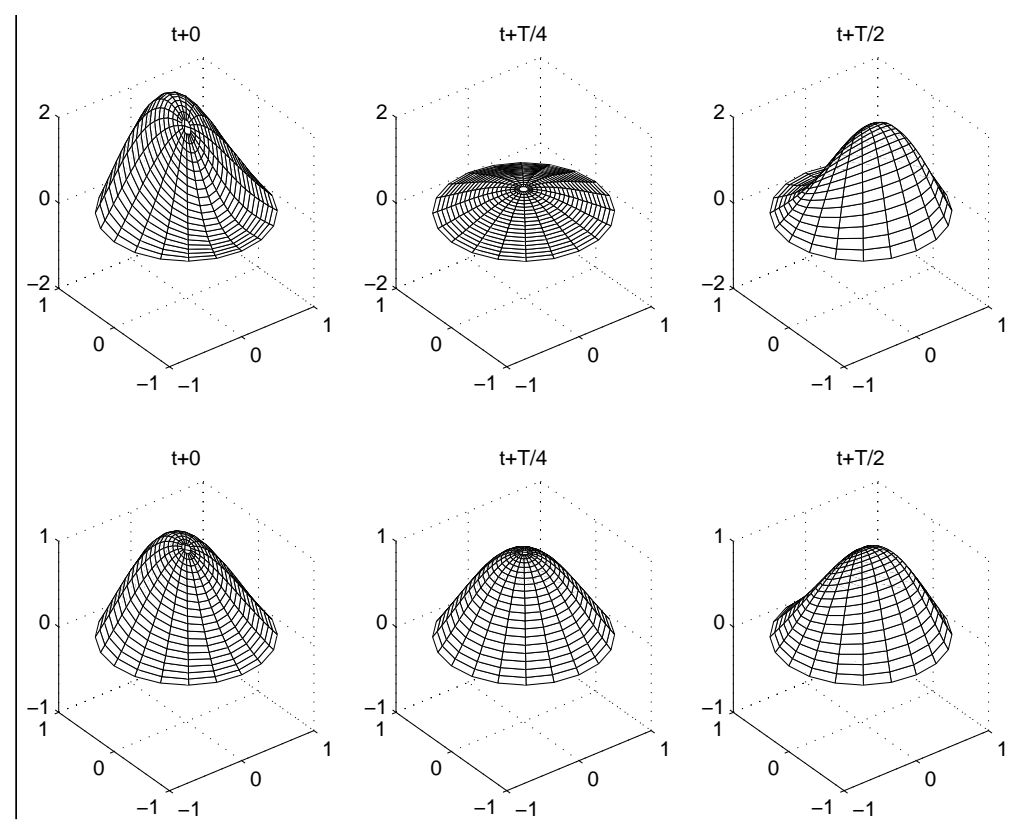

Figure 2. Example of out-of-phase oscillations. a) Upper row: combined fundamental and first harmonic; b) Lower row: harmonic dominant oscillation.

In the NEER project expanded HRS [31, 34, 40,53], the physical response of the research reactor provides the response of the fundamental mode $n_{0}$ represented by Equations 5 and 6 and the first harmonic represented by Equations 7 and 8 are simulated. The fundamental and first harmonic mode 
amplitudes are directly coupled. Void reactivity feedback to the fundamental and first harmonic are provided through separate boiling channel simulations where the boiling channel for the firstharmonic uses a constant core pressure-drop assumption which can have a destabilizing effect.

The Hybrid Reactor Simulation computer system was upgraded from a Sun Microsystems SPARC computer system to a high-performance Windows NT PC workstation. The Mathworks Real-time workshop is used to implement and control the linear reactivity feedback models interfaced to the ECRD in the real-time system. This architecture is adequate for real-time implementation of parallel boiling channels and modal reactor kinetics.

The Penn State thermal-hydraulic test loop was constructed to mimic the boiling phenomena of a Simplified Boiling Water Reactor (SBWR), an advanced reactor design concept, in a unique atmospheric pressure facility where flow visualization is afforded by borosilicate glass piping. Electrically heated rods take the place of the nuclear reactor fuel. The design and construction of the testloop had been a prior multiyear undergraduate design project. The hybrid test-loop simulation (HLS) is diagrammed in Figure 3. In comparison to the HRS, the HLS uses the physical response of a boiling channel to provide feedback to a simulation of reactor kinetics. For core-wide stability characteristics, the simulation utilizes point kinetics. For out-of-phase stability characteristics, the simulation utilizes modal kinetics for both the fundamental and first harmonic modes. The test-loop provides the boiling channel feedback signal to the fundamental mode whereas a boiling channel simulation constrained with constant core pressure drop provides the feedback to the first harmonic mode. 


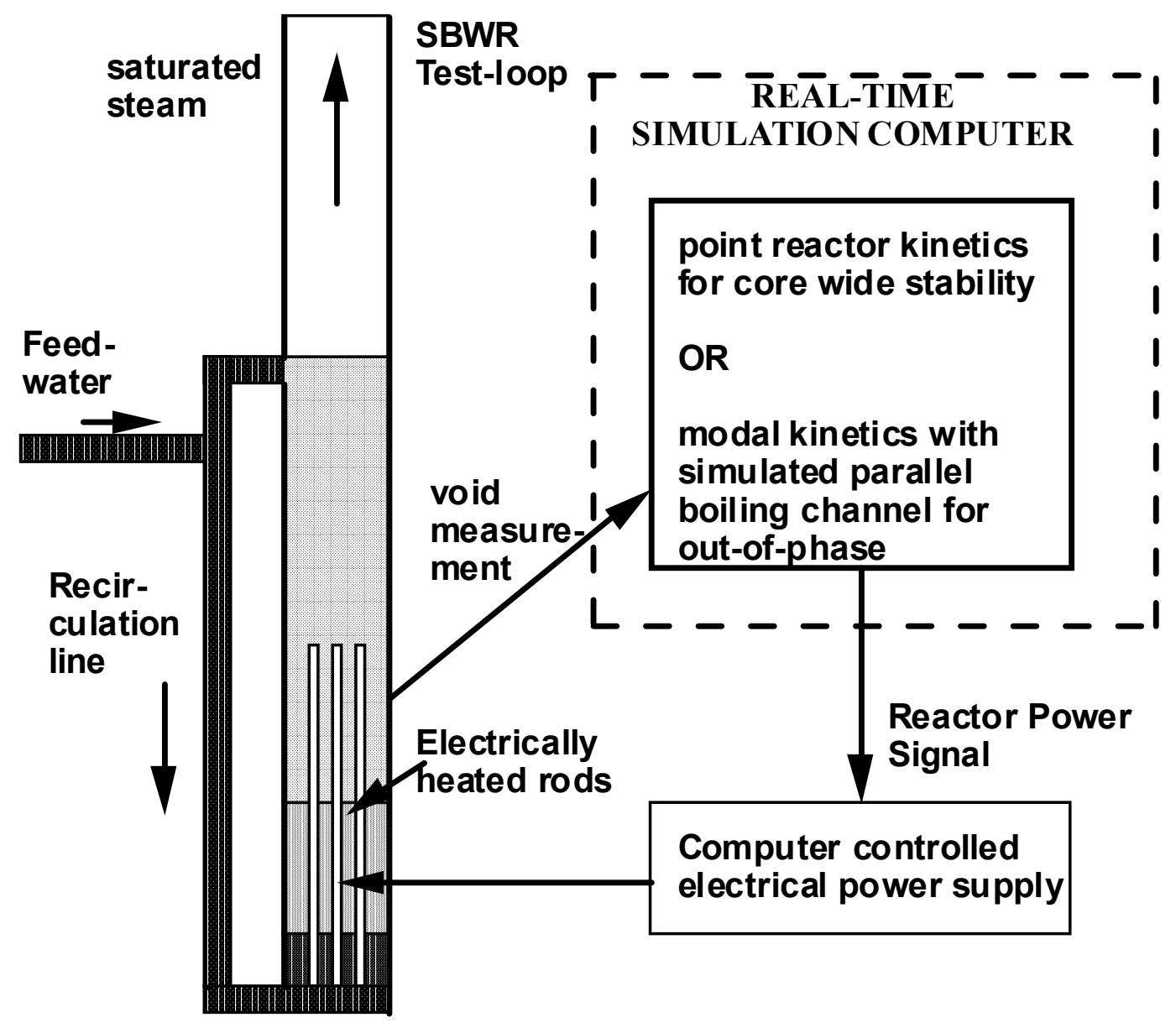

Figure 3. Hybrid Test-loop Simulation (HLS)

A third configuration for hybrid simulation is shown in Figure 4. The purpose of a Hybrid Reactor Test-Loop Simulation (HRLS) is to electronically couple the reactor and test-loop to minimize the need for computer simulation of physical processes to obtain BWR stability characteristics. For core-wide stability, the real-time simulation computer could process the measured void distribution as a reactivity effect to drive the ECRD and process the measured reactor power to drive the power supply for the electrically heated rods of the test-loop. For out-of-phase behavior, the firstharmonic reactor-kinetics mode and its associated boiling channel is simulated. The flexibility to work with any of the configurations is desirable to take into account availability of the test-loop and reactor and the need to focus on specific physical processes in monitoring, operations and control research. 


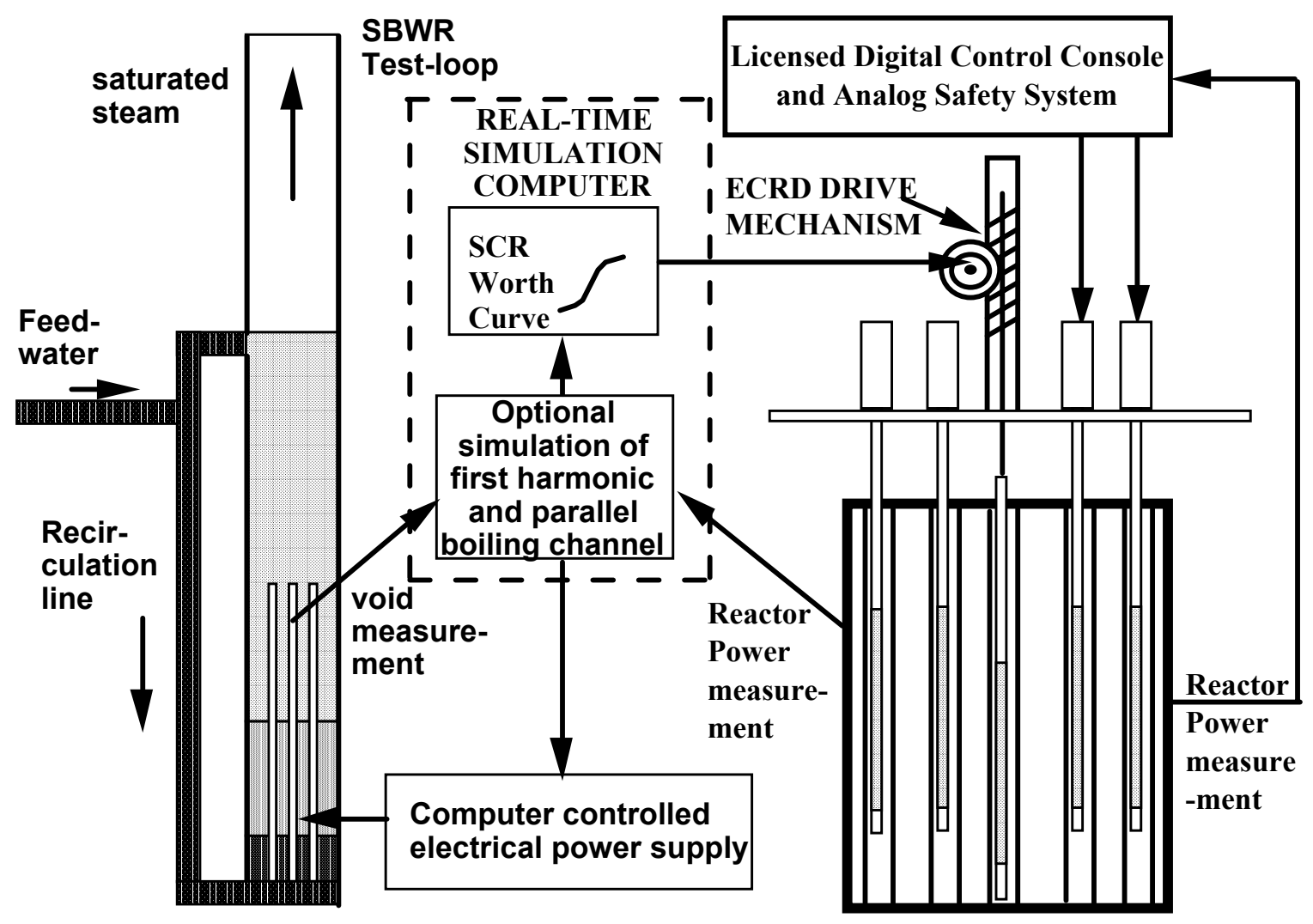

Figure 4. Hybrid Reactor Test-loop Simulation (HRLS) 


\section{OBJECTIVES AND SCOPE OF WORK}

The project was organized into 12 goals in four phases over the planned three-year project.

\subsection{Phase 1:}

Phase 1 was conducted from July 1, 1999 to June 30, 2000 and was comprised of four goals. The first goal was to upgrade the existing Experimental Changeable Reactivity Device (ECRD) and characterize its dynamics. An ECRD is implemented as a TRIGA reactor moveable experiment where an aluminum tube containing an absorber material is positioned within the central thimble of the reactor by an experimental setup. With the completion of this goal, two ECRDs are available for experimental monitoring and controls research. The original ECRD (ECRD \#1) is worth approximately $\$ 0.35$ and the new ECRD (ECRD \#2) is worth approximately $\$ 0.94$. ECRD \#1 is used in experiments at power (up to $65 \%$ ) where temperature changes produce significant reactivity changes. ECRD \#2 was constructed for use at low power (less than 0.1\%) where temperature change and its reactivity effect are negligible. The development of ECRD \#2, which operates much more closely to the TRIGA reactor technical specification, was not a trivial exercise. The reactor facility staff performed a safety analysis, which was reviewed by the Penn State Reactor Safeguards Advisory committee. The reactor staff constructed the device and developed and executed the procedures to initially characterize its dynamics. ECRD \#2 is worth approximately $\$ 0.94$ and can be moved the length of its travel in approximately 3.5 seconds. An experimental worth curve shows that the ECRDs' differential worth is highest when approximately three-quarter inserted where the control rods do not shadow it.

The second goal was to convert an existing hybrid reactor simulation (HRS) capability using MATLAB real-time workshop to Windows NT platform. An HRS is implemented when a real-time simulation of BWR reactivity dynamics positions an ECRD and causes the TRIGA-reactor observed power response to mimic stability phenomena actually encountered in BWRs. Hybrid simulation in

this context refers to the use of the research-reactor time response as an analog solution to the neutron kinetics equations. The TRIGA reactor's solution for the power response is used as an input signal to a real-time digital simulation of power-reactor thermal-hydraulics, which in-turn provides a reactivity feedback signal to the TRIGA through positioning of an ECRD. Figure 5 presents a top-level display 
of a HRS implemented in the current environment. The input signal to the block labeled ECRD+TRIGA is a reactivity rate signal in cents/second. A voltage signal is computed within the block and sent to the ECRD motor drive where it is processed as a velocity command. The reactor power output signal of the block is obtained by digitizing a voltage from a micro-micro ammeter driven by a CIC. All input and output signals used by the experimenter are independent and isolated from the licensed digital

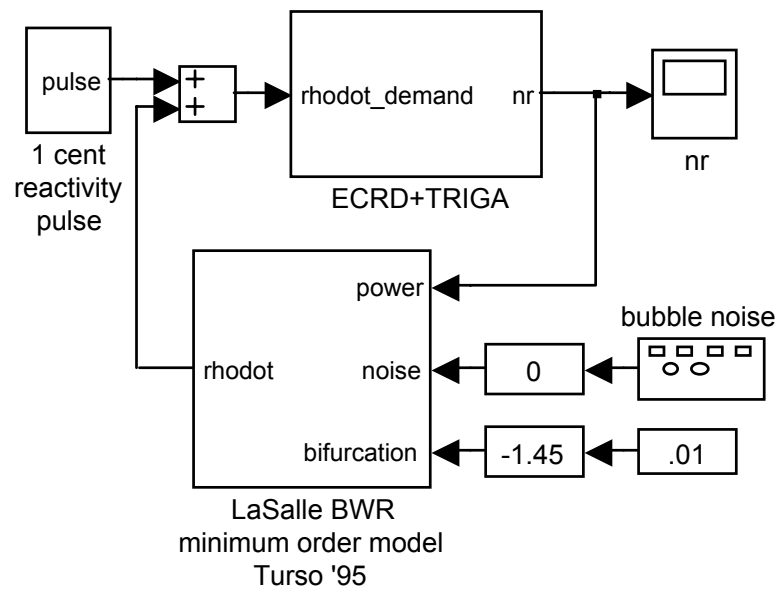

Figure 5: SIMULINK Program for HRS control and analog safety system.

The previously developed HRS used a now obsolete UNIX-network microprocessor-based control system. The conversion to the PC platform was needed to obtain currently available high performance computing to achieve real-time performance of high fidelity boiling channel simulations, as well as better supported application software. A Pentium $550 \mathrm{MHz}$ and an AMD $1000 \mathrm{MHz}$ PC computer were obtained and can be operated in two configurations for experiments. A National Instruments data acquisition card is installed in the AMD computer. It can be operated in a standalone mode where the graphical user interface and real-time application operate on the same computer using the MATLAB real-time workshop windows real-time target option. The second mode uses the MATLAB xPC real-time target option where a special real-time operating system is loaded on the AMD and it communicates with a windows-based graphical user interface on the Pentium computer.

In addition to converting the previous HRS simulation, other important HRS experiments involving optimal control, robust control, and optimized feed-forward control were also readily converted to the PC platform.

The third goal was to develop real-time detailed simulation of commercial BWR boiling channels and modal kinetics in the HRS [31, 34, 40, 53]. Ceceñas-Falcón's boiling channel model [7] was converted to the real-time execution requirements of the MATLAB real-time workshop. This conversion 
required extensive revision of MATLAB m-file programming to required SIMULINK C-mex Sfunction programming. The converted model can now be readily incorporated in HRS simulation. A block representing a detailed boiling channel model simply replaces the block labeled "minimum order model" in Figure 5. The boiling channel models for Vermont Yankee and LaSalle utilize 20 axial nodes to implement nonlinear first-principles conservation of mass, momentum, and energy equations. The model makes extensive use of water and steam properties tables and is thus computationally intensive. Nonetheless, the model's real-time performance on the AMD $1000 \mathrm{MHz}$ computer is excellent and readily allows the simulation of two (or more) boiling channels for hybrid reactor simulation of BWR out-of-phase oscillations. Out-of-phase BWR behavior is implemented in the HRS by using the TRIGA reactor to obtain an analog solution of the in-phase (or fundamental mode) dynamics while the out-of-phase (or first-harmonic mode) amplitude is simulated. The coupling of the simulated out-of-phase mode to the TRIGA generated in-phase mode is achieved by appropriately modifying the reactivity rate signal to the ECRD. Simulated void reactivity feedback paths are provided for each of the fundamental and first-harmonic modes.

The fourth goal was to develop an initial hybrid testloop simulation (HLS) to utilize simulation of point kinetics interfaced to the HLS heater rods. The Penn State thermal-hydraulic testloop mimics the boiling phenomena of a Simplified Boiling Water Reactor (SBWR), an advanced reactor design concept, in a unique atmospheric pressure facility where flow visualization is afforded by borosilicate glass piping. Electrically heated rods take the place of the nuclear reactor fuel. The design and construction of the testloop has been a multiyear undergraduate design project that entered an operational phase with manual or open-loop control of the electrically heated rods.

The initial HLS was implemented using the existing testloop computer and data acquisition system, a $250 \mathrm{MHz}$ Pentium computer. The testloop computer uses data-acquisition cards from Computer Boards Inc, which are not all currently supported for use with the MATLAB real-time workshop. The initial HLS was implemented with National Instruments LabView software. LabView provides extensive graphical interface development tools and includes the capability to create a virtual interface for world-wide-web based experiments. Some work in a separate DOE reactor-sharing project at Penn State has already demonstrated the LabView web-based interface to an undergraduate reactor 
oscillator experiment. An example of using LabView for web-based virtual experiments that we look to can be found at http://vll.phys.dal.ca/.

Although LabView provides a rich operator interface environment, it does not appear to presently offer MATLAB's ease of implementing complex real-time computationally intensive simulations, such as a boiling channel. (The LabView interface for the initial HLS is shown in Figure 6.) Conversely, MATLAB provides a rich environment for implementing real-time computationally intensive simulations but does not appear to offer LabView's ease of implementing a sophisticated operator interface.

In the initial LabView-based HLS, measurements of void fraction and temperature from thermocouples embedded in the heater rods provided feedback signals to adjust reactivity of a simulated reactor kinetics response. The simulated reactor kinetics response was then used to set the electrical power delivered to the heater rods. A simulated control rod position is provided for manual control of the HLS in an analogous manner as a reactor. As the operator moves the simulated control rod, the physical fuel-temperature and void measurements generate simulated reactivity feedback to bring the HLS to new stable power levels. Some interesting opportunities for additional research to enhance the HLS include distributed-parameter estimation of void distribution along the length of the fuel bundle and processing of the temperature measurements to identify and filter the effects of spurious or failed thermocouple readings. 


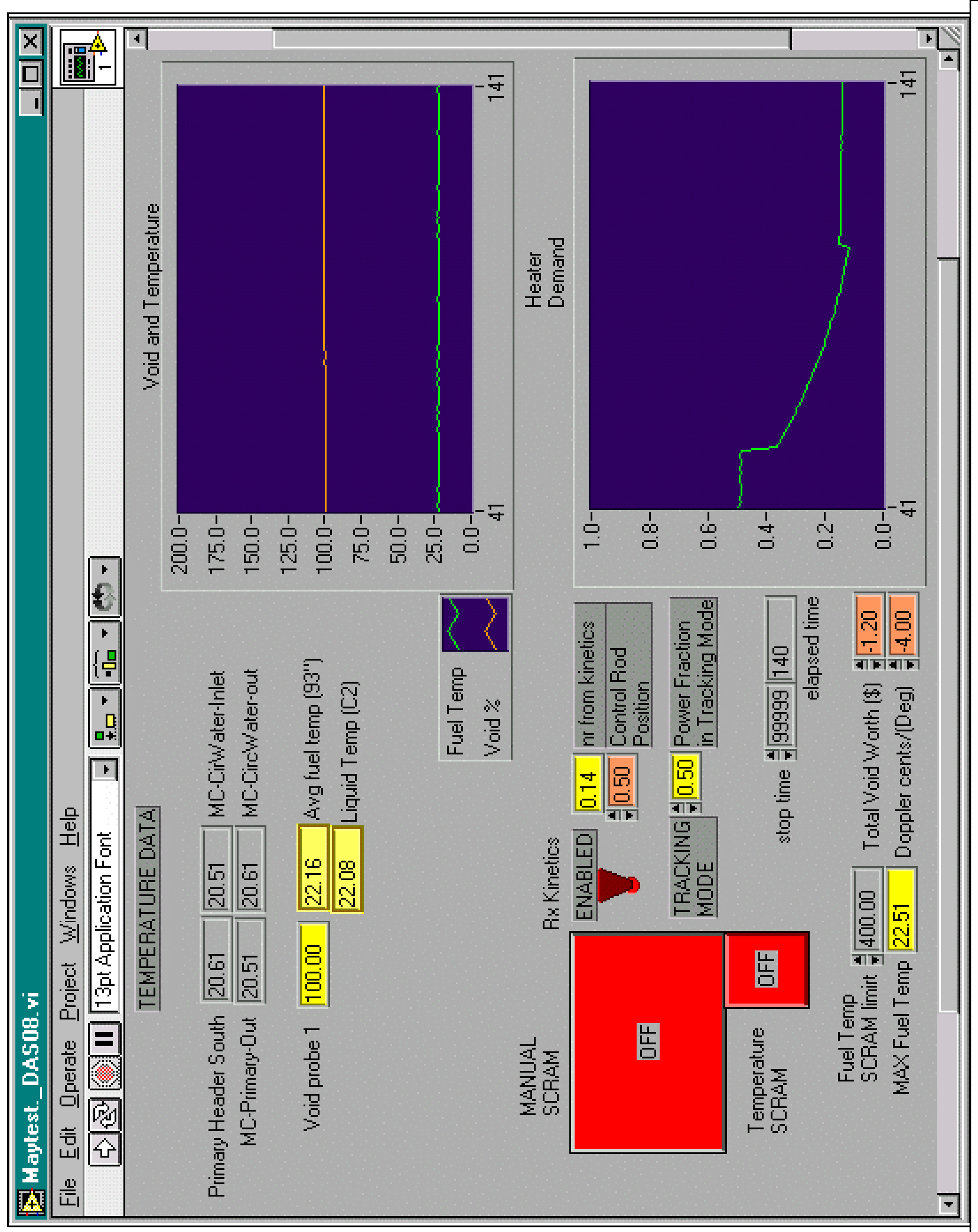




\subsection{Phase 2:}

Phase 2 was conducted in the six month period from July 1, 2000 to December 31, 2000 and was comprised of two goals.

The first goal was to evaluate an on-line uncertainty monitoring system for a robust reactor controller in the research reactor environment, Figure 7. The robust control Performance Weighting Function is used in an on-line filter to provide information to help determine the performance of the controller. A real-time nonlinear simulation model of the plant operates in parallel with the plant. The error signals between Power Demand Signal and plant output and between Power Demand Signal and simulated plant output are inputs to the Performance Weighting Function filters. Fuzzy logic is further used to process the outputs of the filters to provide a measure of the controlled system performance. Switching to predefined robust control for different operating ranges can make accommodation of anomalous events, such as excursions into different operating regions.

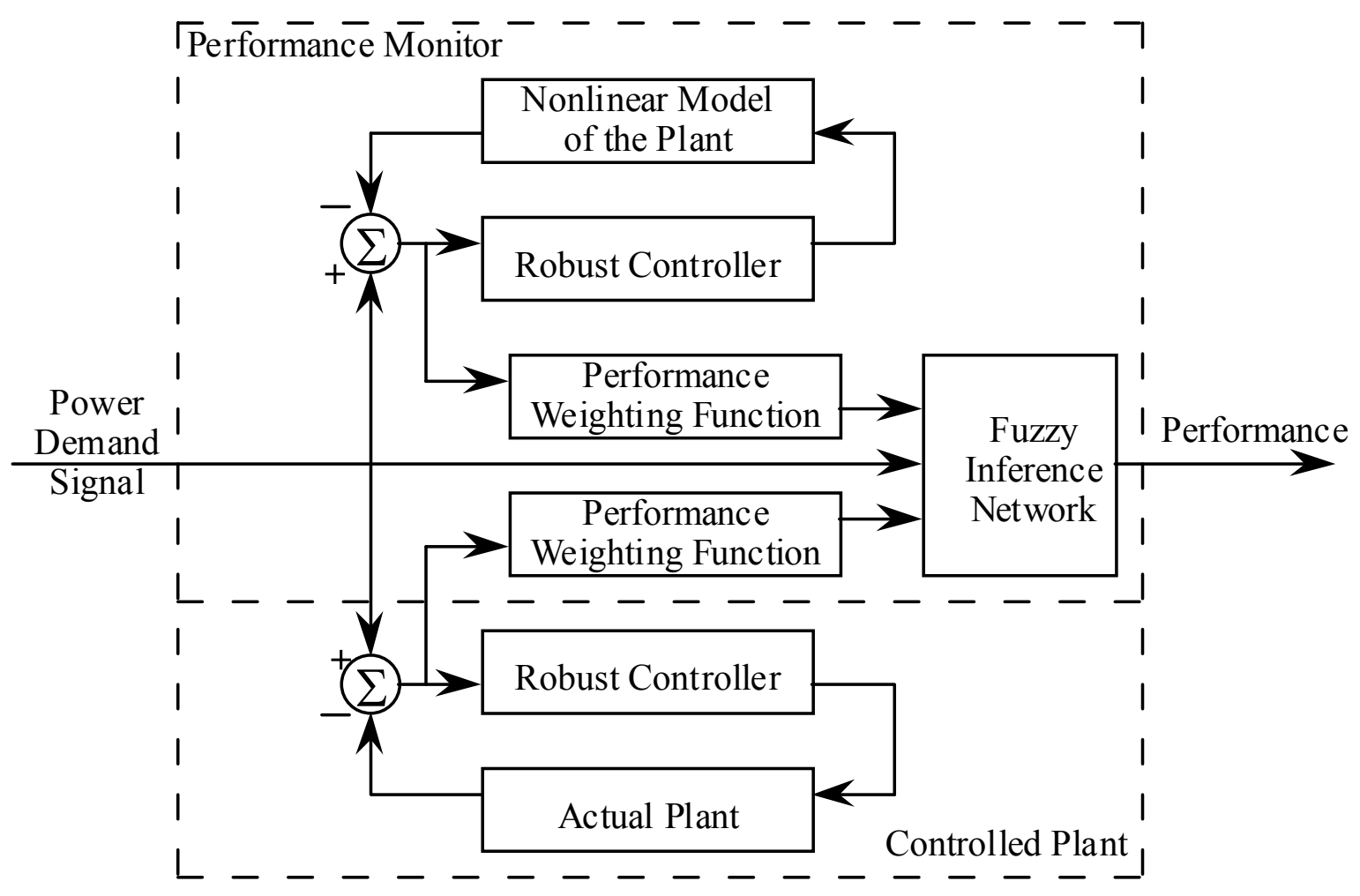

Figure 7. Robust Control Performance Monitor 
TRIGA reactor experiments were conducted during Phase 2 to evaluate on-line performance monitoring techniques. New robust control designs were developed to better match experimental conditions available in the TRIGA reactor. A two-dimensional nine-region operating space is obtained by combining three operating ranges on reactor power (nr) and Reactivity Velocity Gain (Rvg). On-line performance monitoring experiments are conducted within the Mathwork's MATLAB/SIMULINK Real-time workshop environment. Figure 8 presents the top-level MATLAB/SIMULINK block diagram. The upper part is employed to control the reactor (real plant). The controller block consists of two robust controllers. The switch block is used to determine which controller is to be used. The lower part provides real-time simulation of the transient in parallel to the reactor experiment, where a nonlinear reactor model is used.

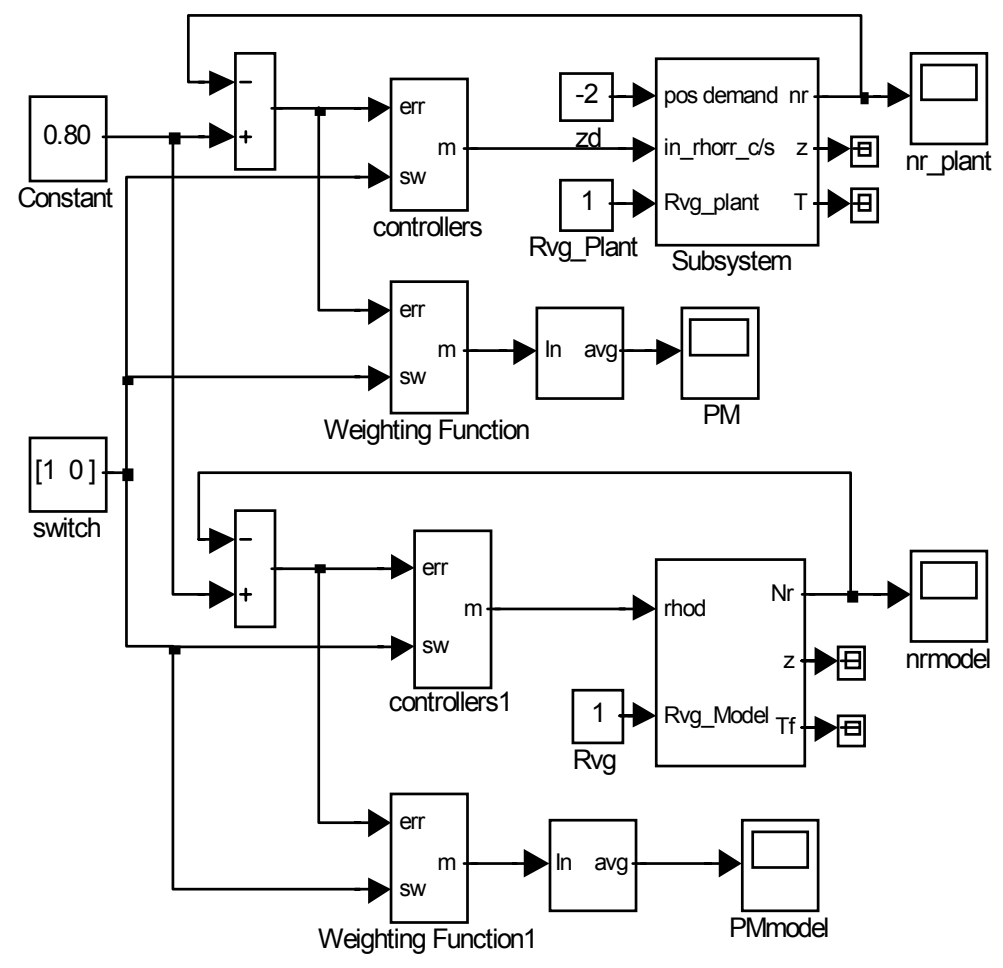

Figure 8. On-line Performance Monitoring Experiment Setup

Some experimental results are presented in Figures 9 and Figure 10. Figure 9 shows the experimental results using the controller designed for the operating range OR21, where the relative power (nr) range is from 0.7 to 1.0 and reactivity velocity gain ( $\mathrm{Rvg}$ ) range is from 0.75 to 1.25 . The top two figures present the power response and corresponding output from 
performance monitor (PM) with Rvg=1.0. The bottom figures give the experimental results obtained with Rvg $=0.5$, which is out of the design range of the controller for OR21. Figure 10 presents the experimental results using the controller designed for the operating range OR31, which is defined as follows: $\mathrm{nr}=\left[\begin{array}{ll}0.7 & 1.0\end{array}\right]$; Rvg $=\left[\begin{array}{ll}1.25 & 1.75\end{array}\right]$. According to these experimental results, the PM output shows a larger magnitude and a larger "pulse" width when a controller is working out of its design operating range. These robust-control performance-monitoring characteristics can be incorporated in an on-line decision making process to choose appropriate robust control selection and enforcement.
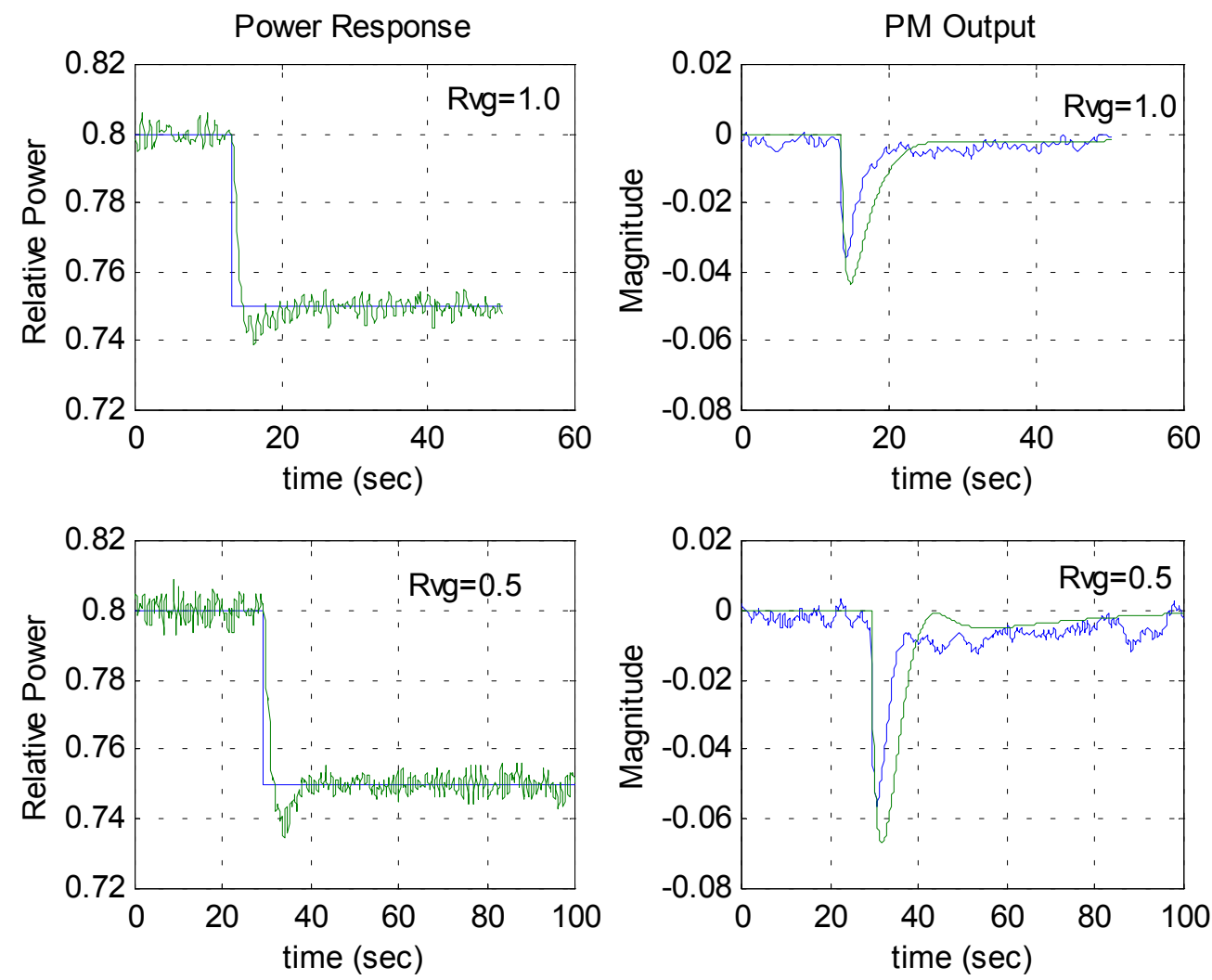

Figure 9: Experimental Results with the Controller for OR21 

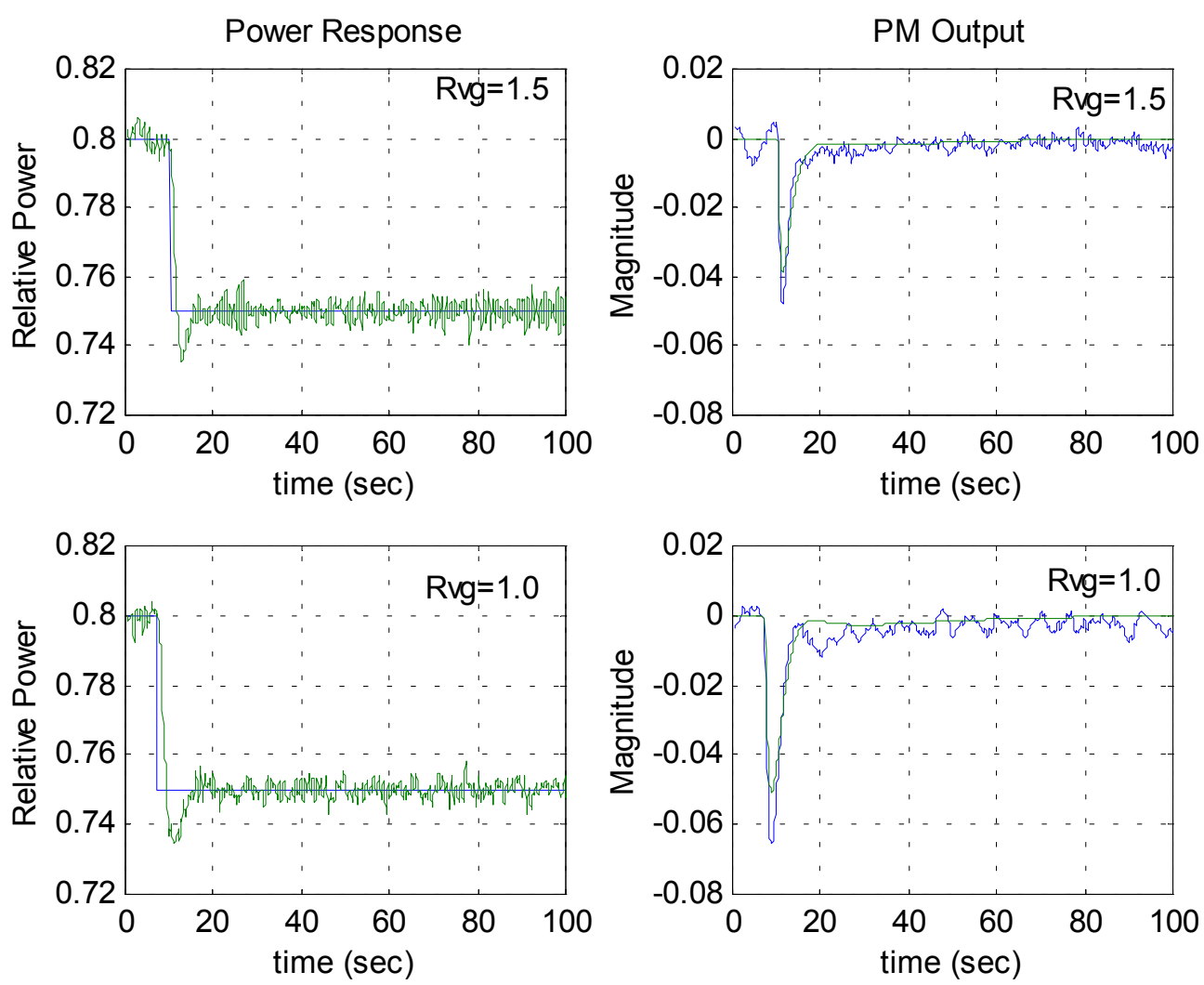

Figure 10. Experimental Results with the Controller for OR31

The second goal was to develop real-time information displays to present the space-time dependent behavior of the out-of-phase reactor BWR stability characteristics [40, 53].

A fast 3-D reactor power display of modal BWR reactor power distribution was implemented using MATLAB graphics capability as exemplified in Figure 11. Figure 11(a) shows the fundamental mode power distribution over the reactor cross-section. Figure 11(b) shows the first harmonic power distribution and Figure 11(c) shows the total power distribution over the reactor.

Due to the large amount of computation for BWR boiling channel simulation and real-time data processing and graph generation, one computer is not sufficient to handle these jobs in the hybrid reactor simulation environment. A new three-computer setup was identified that can efficiently address these requirements and is shown in Figure 12. 


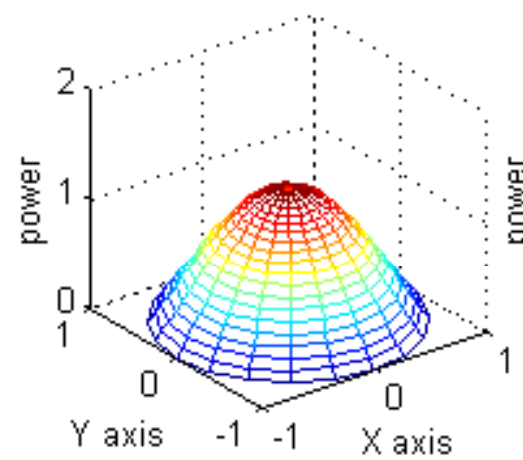

(a) Fundamental mode

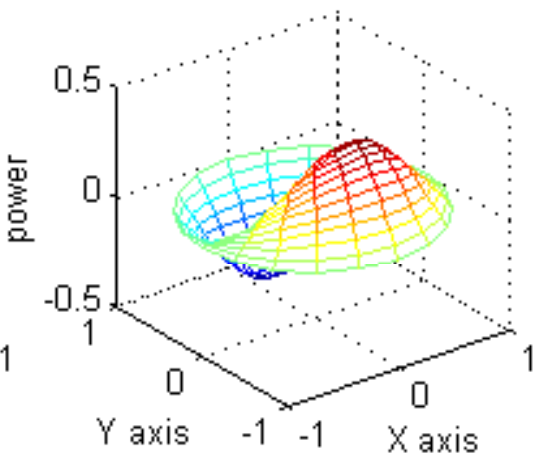

(b) First harmonic

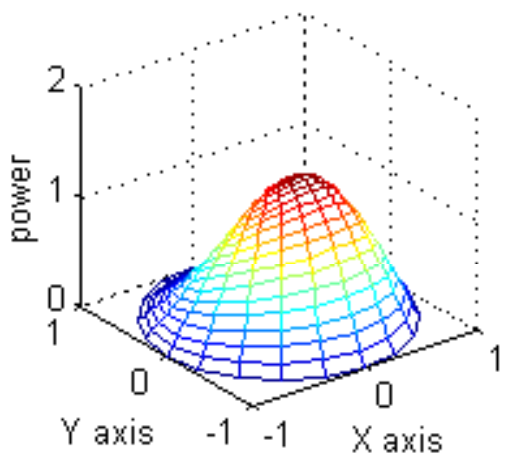

(c) Total power

Figure 11. Example of 3-D real-time information display for BWR out-of-phase (OOP) oscillation (normalized by the initial power)

The host-computer and target-computer work cooperatively under the MATLAB Real-Time Workshop environment. The principal user interaction takes place on the host computer where parameter adjustments are initiated and some elementary information displays are presented. The host-computer and target-computer are connected with network connection; it is therefore possible to separate these two computers over a relatively long distance. The hybrid BWR-simulation application code is generated in the host computer with SIMULINK and is downloaded to the xPC target option of the Real-time Workshop (target computer). The target-computer performs boiling channel thermal-hydraulic simulation and control of the Experimental Changeable Reactivity Device (ECRD) in the TRIGA reactor. The target-computer is connected to the reactor through a $\mathrm{DA} / \mathrm{AD}$ card. The TRIGA reactor power is measured, and a control signal is sent to the ECRD drive mechanism to simulate the BWR reactivity feedback. Desired hybrid simulation of BWRreactor behavior is controlled by adjusting parameters in the host-computer.

The graph computer retrieves data, both measured reactor power, which serves as the fundamental mode power of BWR, and the simulated first harmonic power from the target computer through serial cable connection. Spatial power distribution is calculated from these data and the reactor physics model in the graph computer and 3-D display of BWR reactor power of the two modes together with the total power is displayed there. 


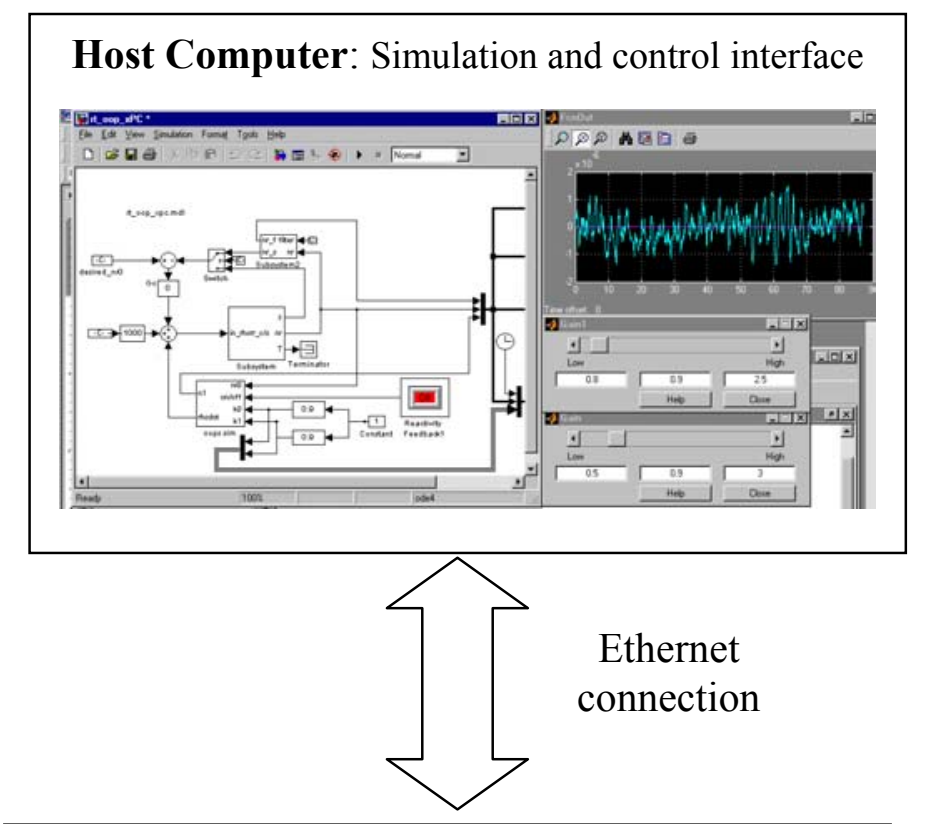

Target Computer: Running xPC application
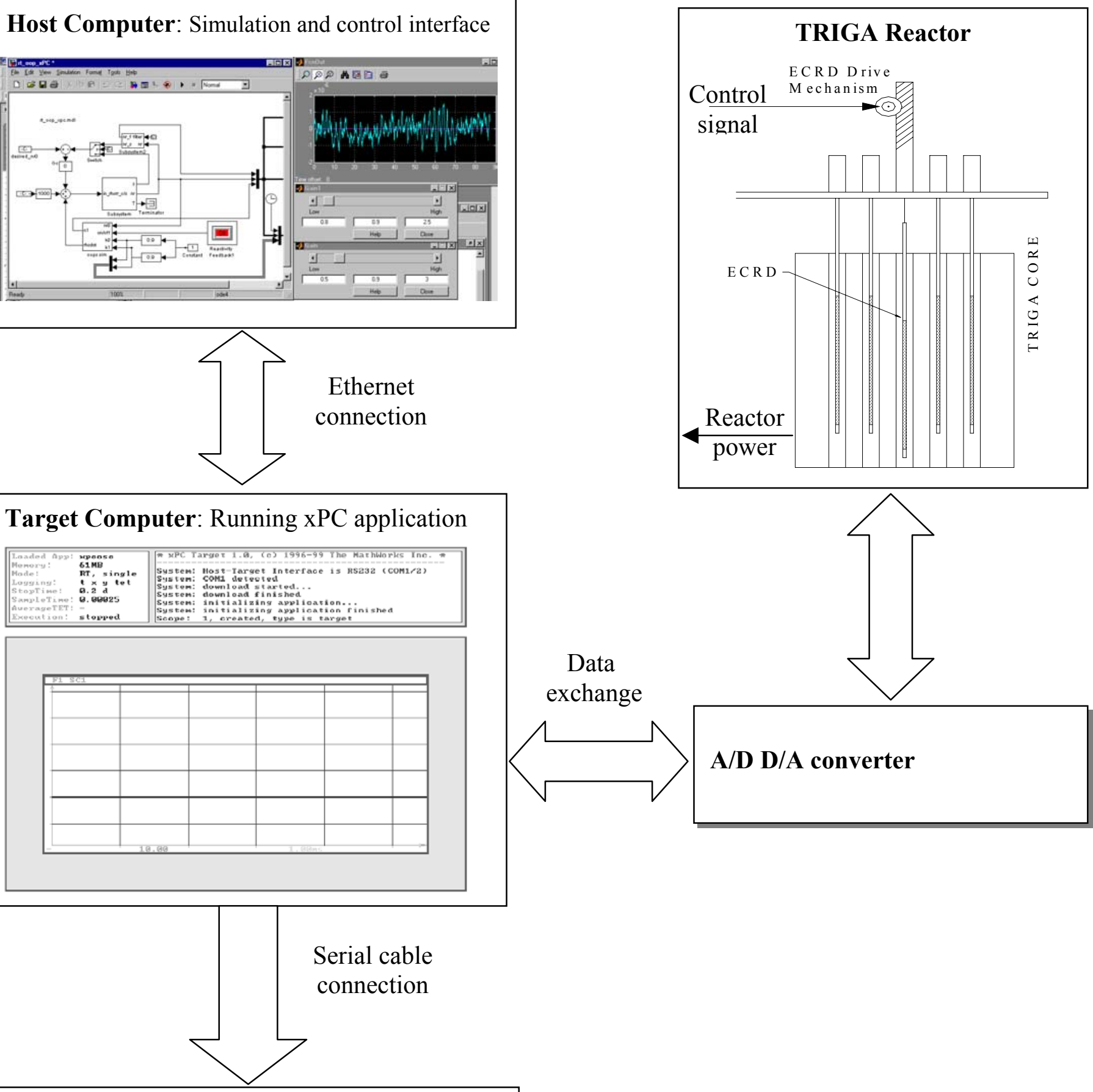

Graph Computer: Data Processing and 3-D display

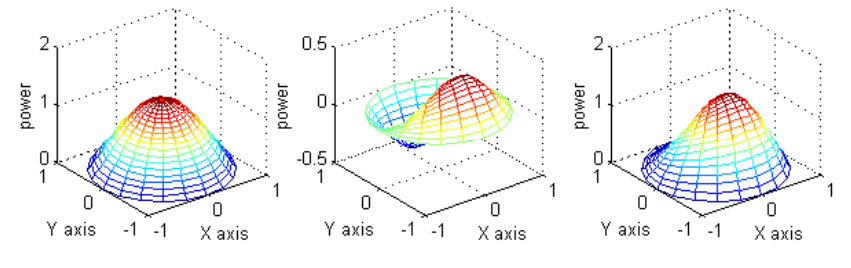

Figure 12. Setup of the experiment for BWR out-of-phase oscillation 3-D information display 
At the end of Phase 2, the graph computer and the host computer functions were implemented in the same $550 \mathrm{MHz}$ computer, thus the refresh interval on the 3-D graph generation was undesirably long. A new $1.5 \mathrm{GHz}$ computer was subsequently added so that the graph functions can be executed at a desirable frequency of $10 \mathrm{~Hz}$.

\subsection{Phase 3}

Phase 3 was conducted in the six month period from January 1, 2001 to June 30, 2001 and was comprised of two goals.

\subsubsection{Expansion of HLS to Modal Kinetics}

The first goal was to expand a Hybrid Loop Simulation (HLS) to incorporate modal kinetics and parallel boiling channel simulation. The thermal-hydraulic test loop used in this work is a one-half height scaled version of General Electric's Simplified Boiling Water Reactor (SBWR). The digitally simulated reactor exploits modal neutron kinetics equations up to the first harmonic, and governing equations are not linearized. The preserved nonlinearity makes the simulated reactor behave more realistically, and eigenfunction expansion to the first order lets half of the core be represented independently. A series of experiments have been performed with the hybrid system including simulated control rod reactivity insertion/withdrawal, cross-mode interaction, etc.

The overall system layout is depicted in Figure 13 and replaces the initial HLS developed in Phase 1. All the state measurements from the Low-pressure Integral Test Facility (LPITF) are collected and processed in the host computer. This computer can also be used to control power input to the heater rods. The Monitoring and Control Interface relays some system state measurements, such as void, differential pressure, and temperature to the target computer. The Target Computer Control Interface relays simulated control rod reactivity $\left(\rho_{r}\right)$ and void reactivity feedback gains $\left(K_{0}, K_{1}\right)$ to the target computer. The target computer in turn returns fundamental mode power $\left(n_{0 r}\right)$ to the host computer, which in turn can apply the signal to change the power of the electrically heated rods in the LPITF. 


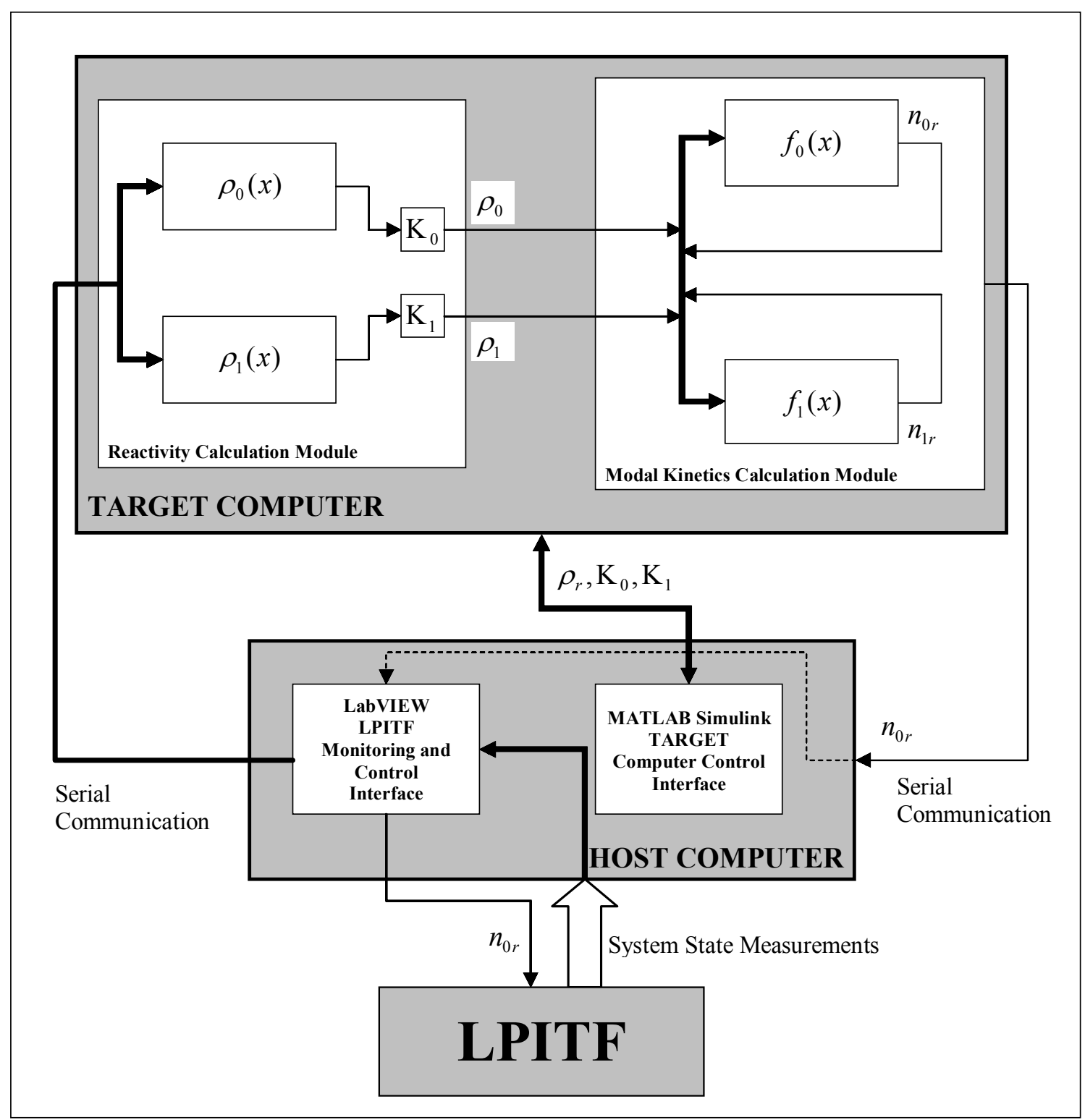

Figure 13. The general structure of the hybrid loop simulator.

The target computer runs the real-time modal reactor simulation application. The communication between the two computers is carried out via internet and serial line. Over the serial line is transmitted the status of the system and the feedback response streams over the same line. Serial communication speed is adequate compared to the system sampling period.

More details on the LPITF, the host computer and the target computer are presented in the following sections. 


\subsubsection{Low-Pressure Integral Test Facility (LPITF)}

The LPITF is a half-scaled version of General Electric's Simplified Boiling Water Reactor (SBWR) operating at near atmospheric pressure (Figure 14).

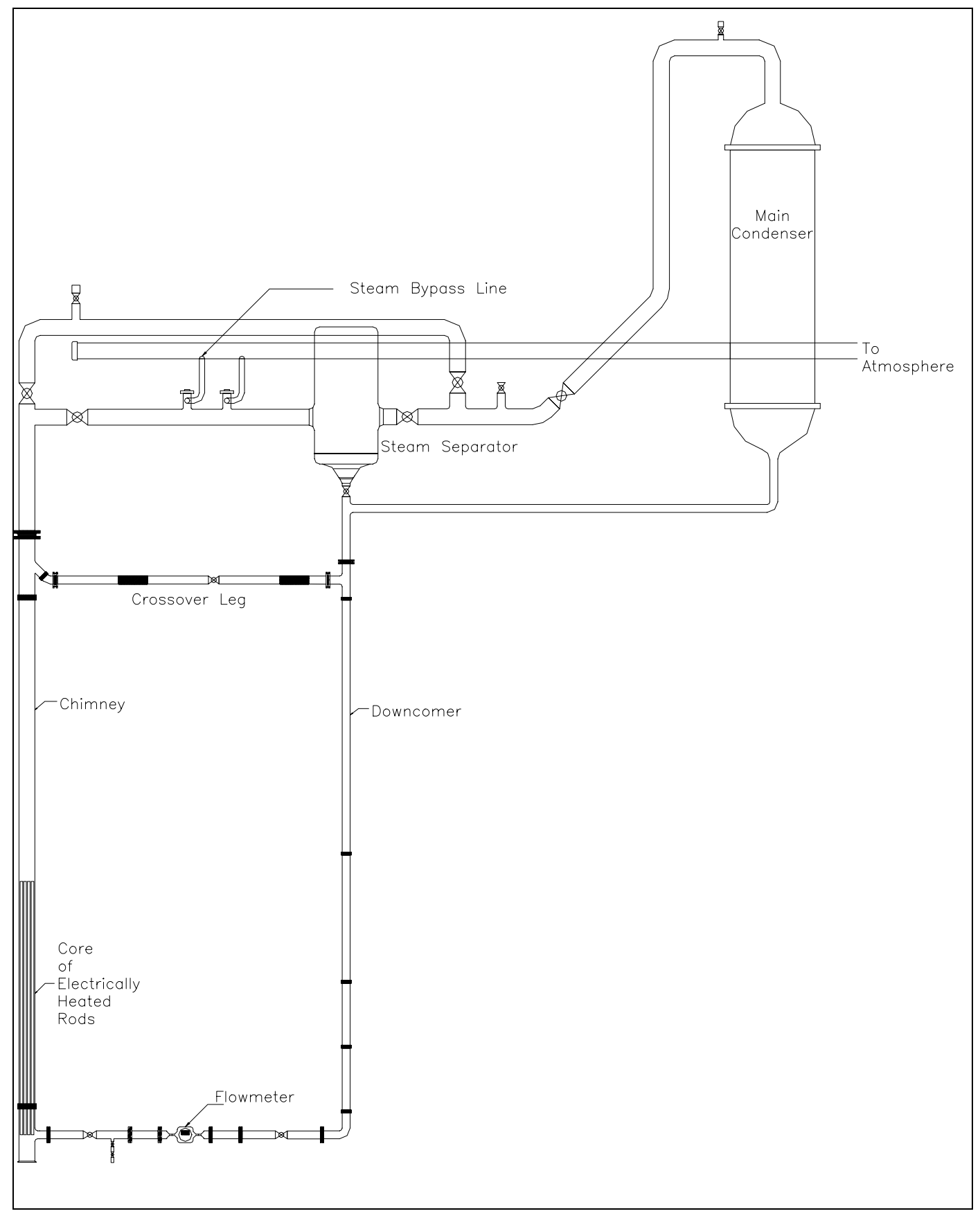

Figure 14. Simplified drawing of the Penn State Low-Pressure Integral Test Facility. 
In addition to the modeling of the reactor core, chimney and downcomer, the test loop also models the emergency core cooling systems (ECCS), gravity driven cooling system (GDCS), and isolation condenser (IC). The IC and GDCS are not used in this work and not shown in Figure 14. The core, chimney and downcomer flows are made visible through borosilicate glass piping. The system is powered by electrically heated rods. The power is supplied over three silicon controlled rectifiers (SCR). SCR's can be controlled from an external unit. The external power control signal is sent from the host computer.

The core of the loop is heated by 12 heater rods; a number calculated through Ishi's scaling law. The rods are manufactured in the same diameter as the SBWR assembly rods, allowing more realistic subchannel analysis. The water flow through the core is mixed by the use of BWR grid spacers.

The LPITF is installed with a number of instrumentation in order to capture the physical state of the system more accurately. Among the instrumentation are a very sensitive magnetic flowmeter for the primary circuit flow, pressure cells around the flow path, fluid and rod surface thermocouples, void probes, and power transducers.

\subsubsection{Host Computer}

Data monitoring and control interfaces have been implemented with National Instruments LabVIEW software. LabVIEW provides a very easy-to-use programming environment, which is fully based on graphical programming, as well as extensive graphical user interface and development tools. LabVIEW also has the capability to create a virtual interface for world-wideweb based experiments. Figure 15 gives a screenshot from the main control diagram. Plot screens

provide visual aid for the important system state variables. At the top on the left-hand side is a power control knob, which determines the power signal to be transmitted to SCR power control units. In this work, the SCRs are balanced so that the power applied to each SCR is the same. 


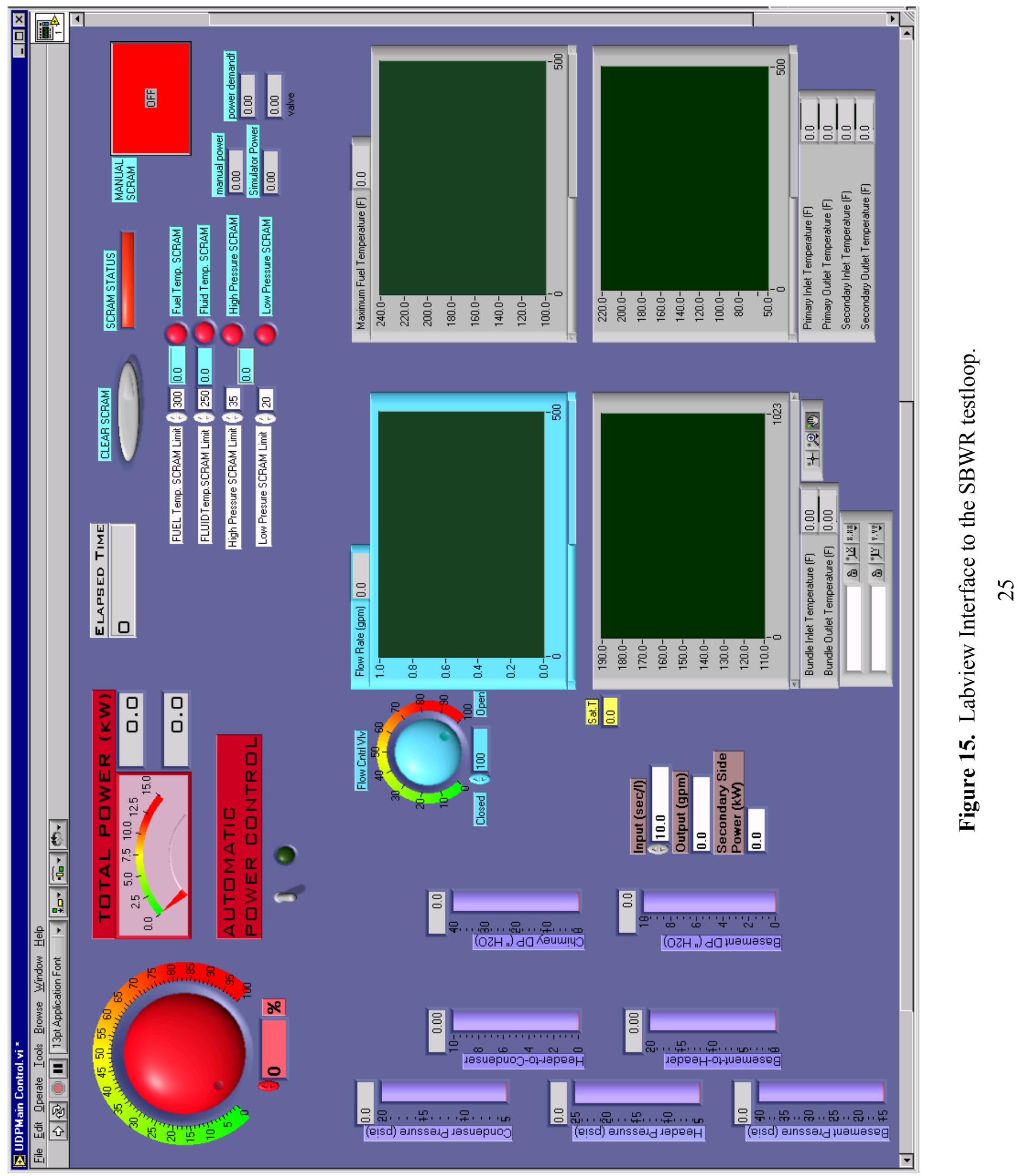




\subsubsection{Target Computer}

Target computer represented at the top of Figure 13 reads measurements data from the host computer over a serial line. The data is processed in real-time and the calculated results are transmitted back to the host computer over the serial line again. The target computer provides real-time simulation of modal reactor kinetics $\left(n_{0 r}, n_{1 r}\right)$ and a detailed boiling channel simulation for the out-of-phase mode reactivity feedback $\left(\rho_{1}(x)\right)$. Void and other measurements from the LPITF are used to set fundamental mode reactivity feedback $\left(\rho_{0}(x)\right)$. The magnitude of the modal kinetics reactivity feedback $\left(\rho_{0}, \rho_{1}\right)$ are multiplied by adjustable gain parameters $\mathrm{K}_{0}$ and $\mathrm{K}_{1}$. The output from the target computer is the fundamental mode power to be applied to heater rods.

\subsubsection{Experimental Procedure And Results}

Since the thermal-hydraulic test loop has borosilicate components, care has to be taken for the pressure limitations. In order to avoid over pressurization in the system, operation is carried out at near atmospheric pressure.

Figure 16 presents the natural circulation driven coolant flow rate during startup and operation of the LPITF. 


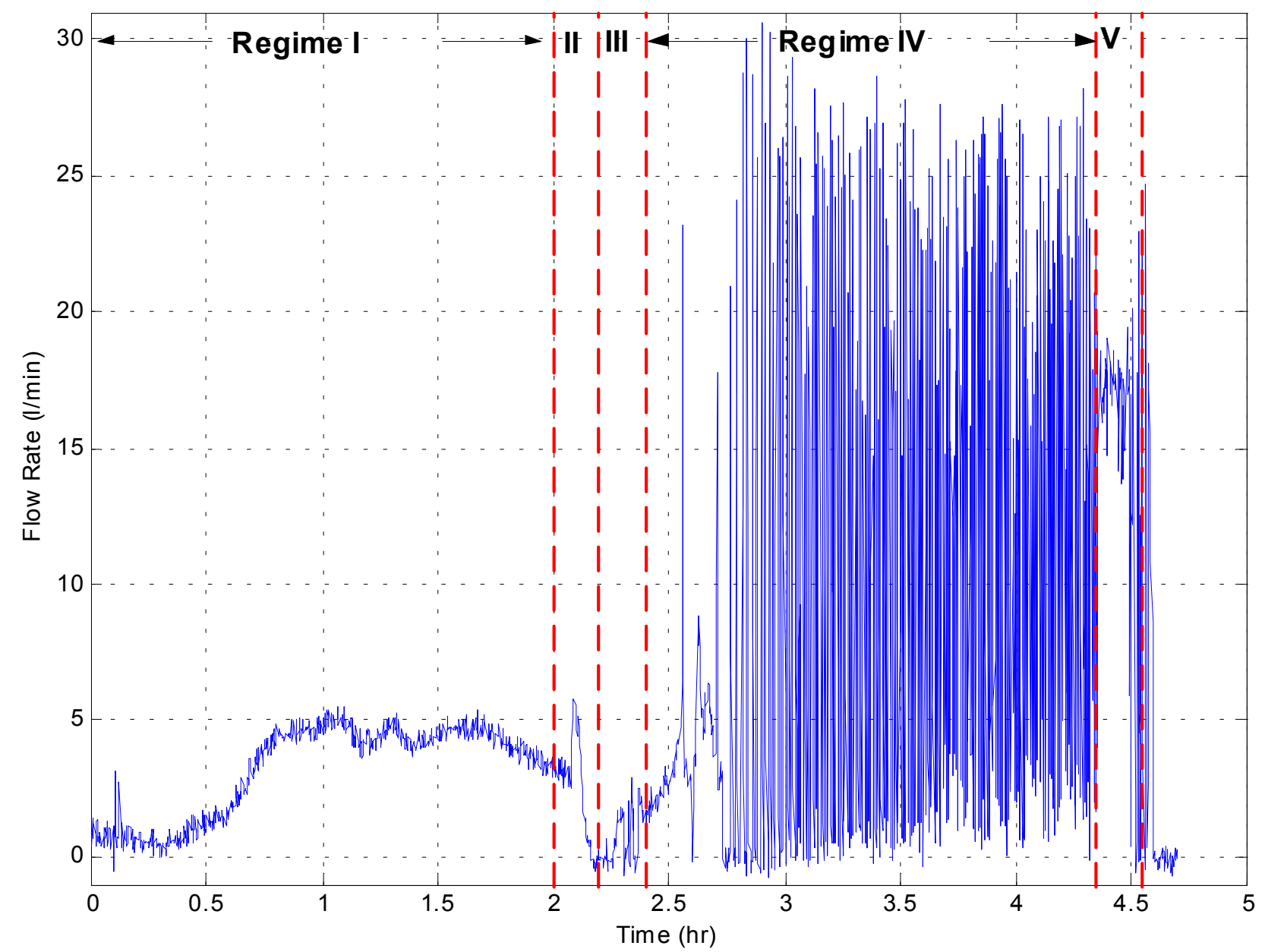

Figure 16. Variation of flow rate throughout the entire test loop operation. The effect of system depressurization can be seen around $2^{\text {nd }}$ hour. Regime I: single phase heating; Regime II: draining a portion of the system inventory; Regime III: system reheat; Regime IV: flow oscillations in two-phase region; Regime V: stable two-phase flow behavior.

The general steps through various regimes can be summarized as follows:

i. The loop is filled with water, and left open to the atmosphere to avoid pressurization; condenser secondary side flow is set to around $20 \mathrm{l} / \mathrm{min}$ in order to help initialize and develop natural circulation with a higher temperature gradient between the two ends of the system (Regime I).

ii. Once the average core temperature approaches $90^{\circ} \mathrm{C}$, power to the rods is turned off; condenser secondary side flow is reduced to around $2 \mathrm{l} / \mathrm{min}$ so as to let the liquid inventory become more homogeneous in temperature. 
iii. The system is closed to the atmosphere.

iv. A drain valve at the lowest point of the loop is opened to slowly reduce water inventory. As water inventory is reduced, the hot water flashes to steam to fill the volume created by the draining liquid. The pressure in the upper portions of the loop drops below atmospheric (Regime II and III).

v. Having drained the water to a desired level -usually just below the cross over leg (Figure ) - power to the rods is slowly increased and the system develops until steady two-phase natural circulation conditions are achieved. System pressure slowly increases owing to continued heat input.

Due to low system pressure and additional heating needed to establish a two-phase natural circulation flow path, the LPITF is unstable in Regime IV indicated in Figure 16. The steady twophase natural circulation regime develops after steam begins to reach the inlet to the condenser.

In Region V, steady two-phase flow, a recirculation flow path is established along the loop through the inlet of the core to chimney to crossover leg (behaves like upper plenum) to downcomer to lower plenum, and core inlet again. Steam flow through the separator, condenser, and liquid return to the downcomer is also established. Power is manually set to $65 \%$ (of the facility's reduced capacity). The communication between the host computer and the target computer is commenced.

Simulated reactor kinetics on the target computer is controlled over the host computer via MATLAB Simulink interface through simulated rod reactivity $\left(\rho_{r}\right)$, fundamental mode gain $\left(K_{0}\right)$, and first harmonic mode gain $\left(K_{1}\right)$. These parameters are adjusted properly to set the simulated power exactly to $65 \%$ prior to connecting the output for fundamental mode power to the heater rods. The power control from LabVIEW is no longer active through its power knob.

\subsection{Data Analysis}

Figure 17 presents the entire operation history for core fluid temperatures. The onset of the second stage of the operation, where system inventory is partially drained and then the bundle 
power is recovered, starts about $2.2 \mathrm{hr}$ after the experiment is commenced. The system stabilizes around $4.3^{\text {rd }}$ hour, about 2 hours after the second stage starts.

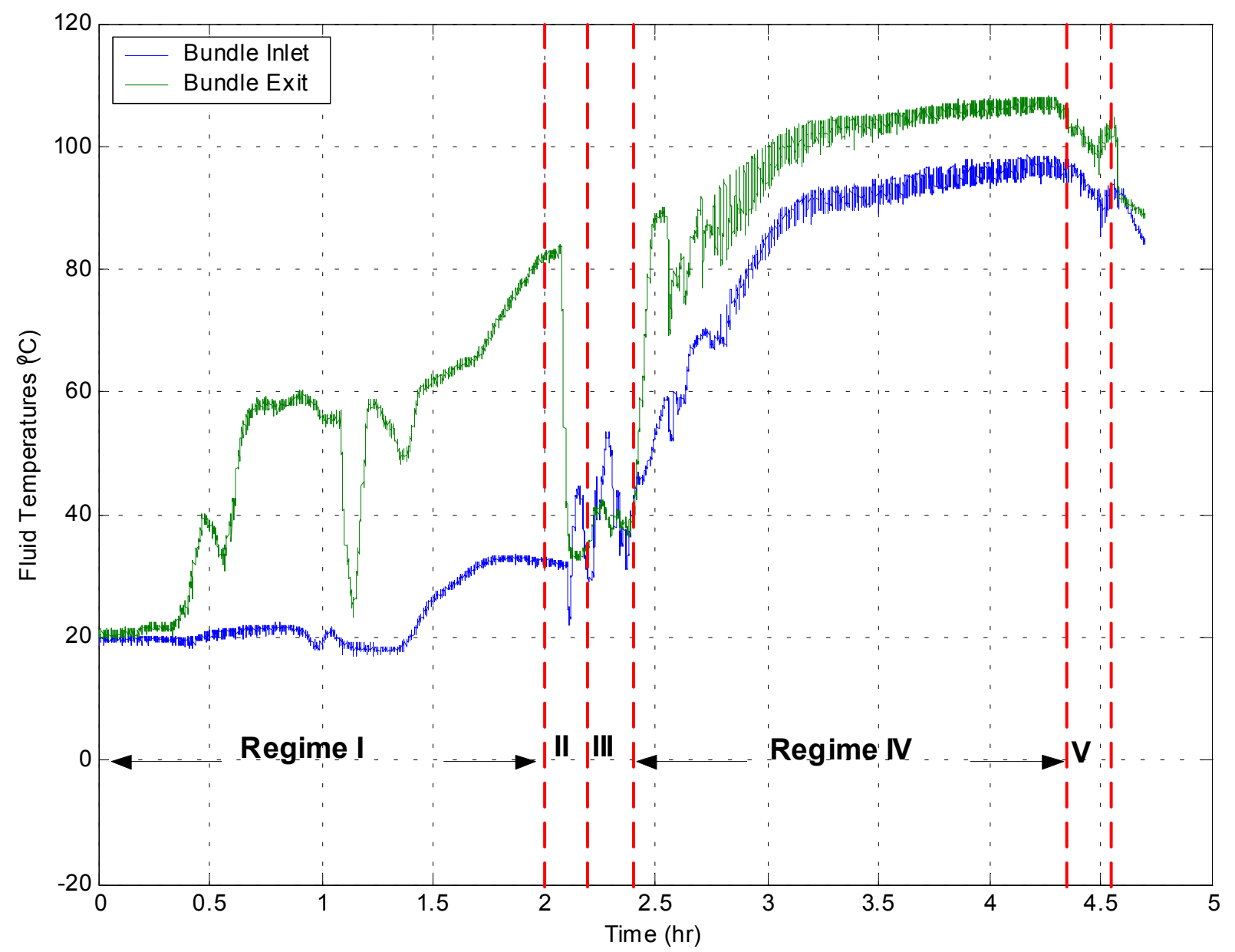

Figure 17. The variation of average fluid temperatures at bundle inlet and bundle exit.

The power control is transferred to the target computer around $4.4^{\text {th }}$ hour and the simulated reactor took over the control for about 5 minutes.

Figures 18 through 20 present the coupled behavior of the hybrid system. These figures are five-minute details from the operation around $4.4^{\text {th }}$ hour. Figure 18 presents simulated rod reactivity $\left(\rho_{r}\right)$, fundamental mode power $\left(n_{0 r}\right)$, and fundamental mode reactivity feedback gain $\left(K_{0}\right)$. 

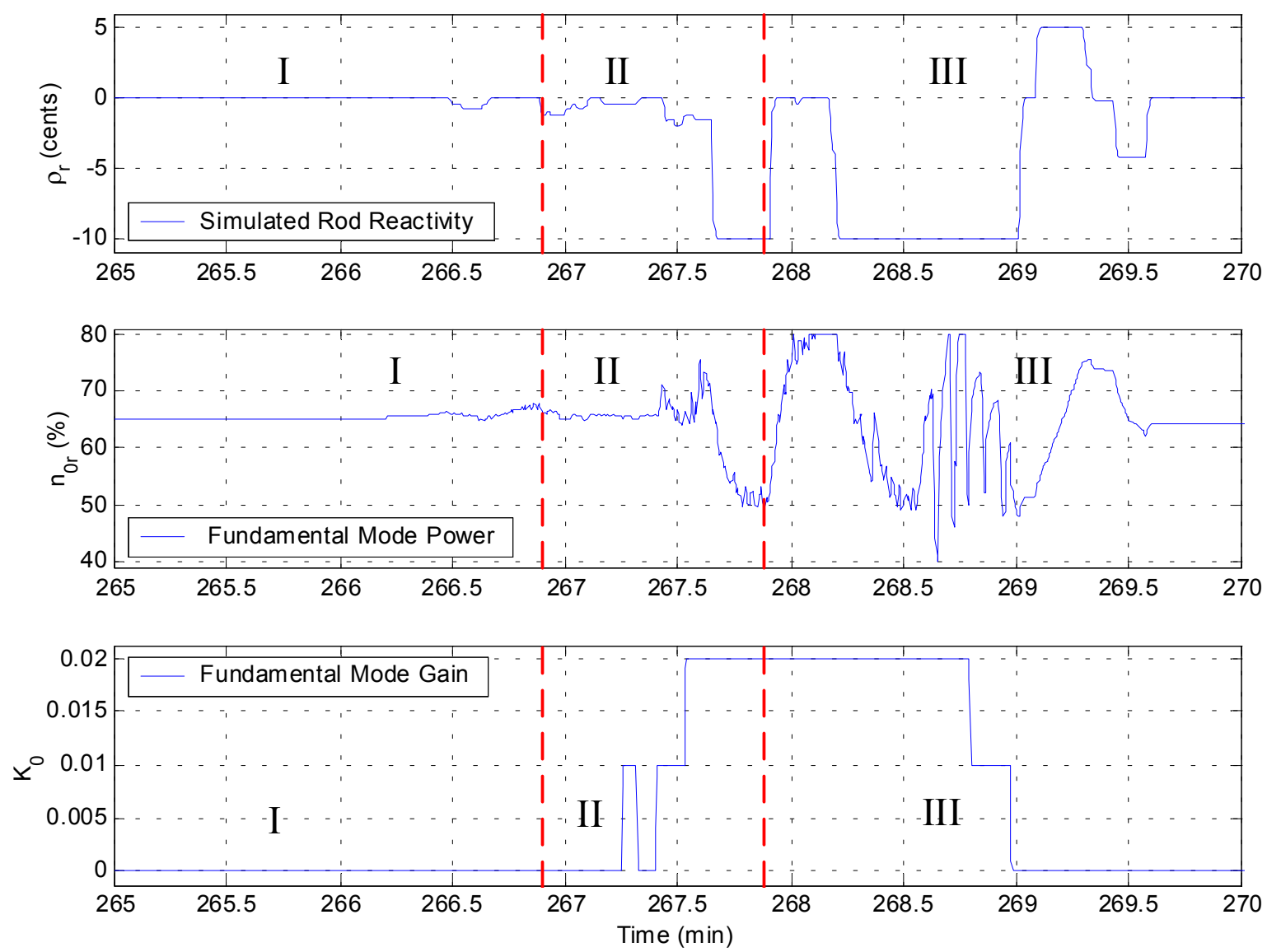

Figure 18. Behavior fundamental mode during the hybrid experiment.

Figure 19 presents first harmonic mode power $\left(n_{1 r}\right)$ and first harmonic mode reactivity feedback gain $\left(K_{1}\right)$. Figure 20 presents fundamental mode reactivity $\left(\rho_{0}\right)$ and first harmonic mode reactivity $\left(\rho_{1}\right)$.

To help understand the response of the system, the hybrid experiment can be analyzed in three regions. Each region shows different characteristic behaviors: The first region is where the fundamental mode reactivity feedback gain $\left(K_{0}\right)$ is kept zero and the system excitation is done through the first harmonic excitation by setting its feedback gain ( $K_{1}$, Figure 19) above the critical value $(\sim 10.65)$. In Region II, the first harmonic gain is set to a sub-critical value $(<10.65)$ and the primary interaction with the LPITF boiling channel is through the fundamental mode void reactivity $\left(K_{0}\right.$, Figure 18$)$ and Doppler feedback. The Region III is basically the same as the Region II, and only differs in the first harmonic gain set back to its critical value. 

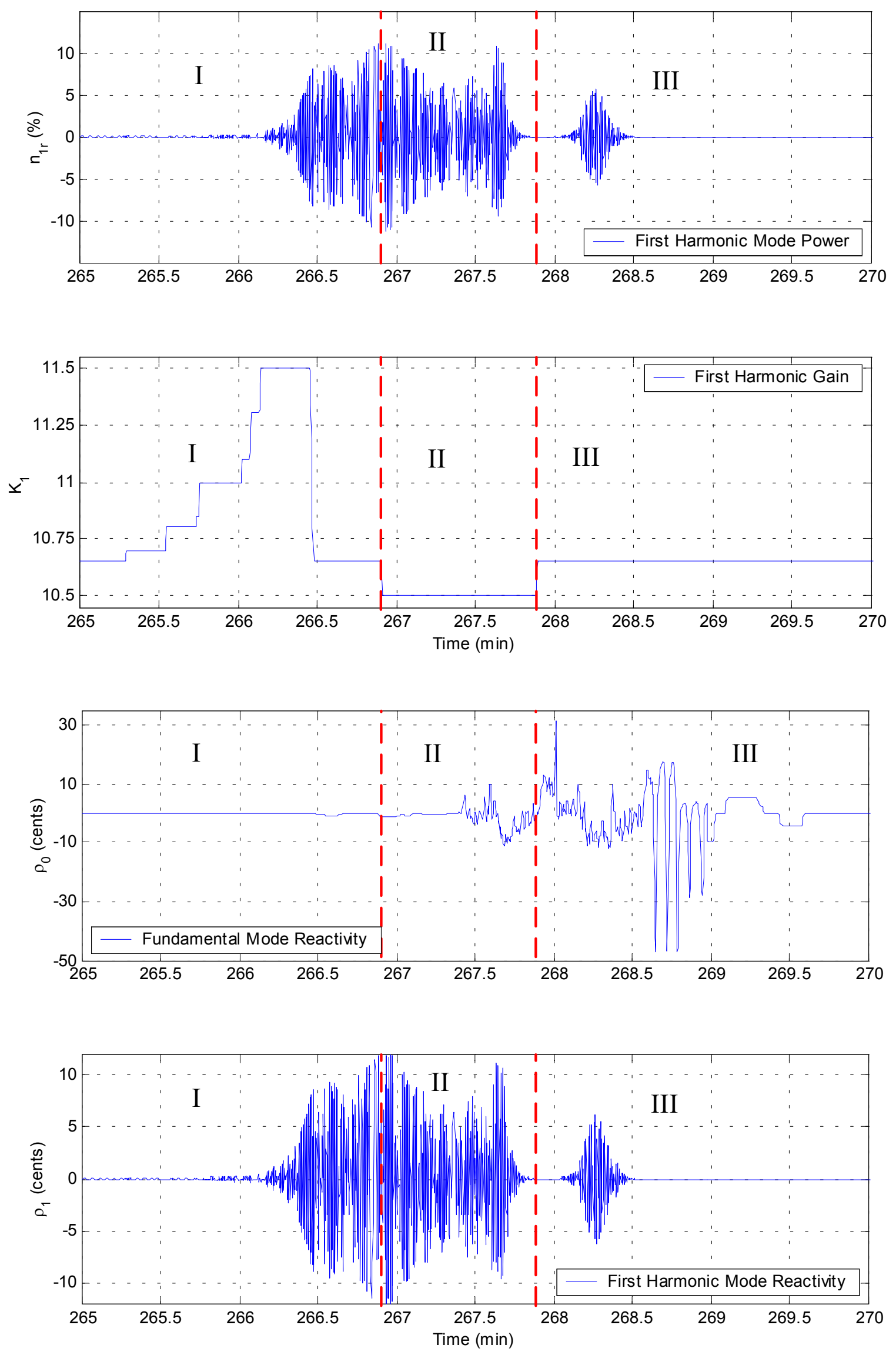

Figure 20. Response of the reactor due to Doppler and void reactivity feedbacks in terms of fundamental and first harmonic reactivities 


\subsection{Region I}

As explained above, the response in the first region is dominated by the out-of-phase oscillations. The lower plot in Figure 19 shows the first harmonic gain $\left(\mathrm{K}_{1}\right)$. The top plot in the same figure represents the first harmonic power and as can be seen, the out-of-phase oscillations become notable around the $266^{\text {th }}$ minute.

An interesting characteristic of this region can be seen in Figure 18, where simulated rod reactivity $\left(\rho_{r}\right)$, fundamental mode power $\left(n_{0 r}\right)$, and void reactivity feedback gain $\left(\mathrm{K}_{0}\right)$ are plotted. The fundamental mode power starts to exhibit a small amplitude frequency component of about $1 \mathrm{~Hz}$ around $266.5^{\text {th }}$ minute, even though the fundamental mode feedback gain is zero. The reason for this oscillation is the cross-mode excitation: The interaction of the fundamental mode with the first harmonic results in excitation in the global power. This is usually observed in real BWR's over the APRM (Average Power Range Monitors) and is an indication of the out-of-phase oscillations.

The additional characteristics of the first region can also be seen in fundamental and first harmonic reactivities, $\rho_{0}$ and $\rho_{1}$, respectively, in Figure 20. The excitation of the fundamental mode through the interaction with the first harmonic results in first harmonic reactivity oscillations, which in turn affects the global power.

\subsection{Region II}

The response of this region is dominated by the fundamental mode Doppler and void reactivity feedbacks. The gain of the first harmonic mode $\left(\mathrm{K}_{1}\right)$ is set to a below-critical value in order to begin to suppress the large out-of-phase oscillations that developed in Region I. The fundamental mode gain $\left(\mathrm{K}_{0}\right)$ is adjusted in order to avoid any sudden power changes. The fundamental mode power is also affected through the simulated rod reactivity insertions, as plotted in the top section in Figure 18. In order to study the void reactivity feedback, power is changed through the simulated control rod, $\rho_{r}$. The response of the reactor to a step decrease in reactivity of $10 \varnothing$ can also be seen in the same region. The fundamental mode power follows the simulated rod reactivity, but with smaller amplitude and higher frequency oscillatory components superimposed. 
These high frequency oscillations result from the interaction with the first harmonic mode. In Region II in Figure 19, the leftover oscillation after the first harmonic gain is decreased to below the critical value is still large enough to affect the fundamental mode power. As fundamental mode power drifts upward, it reinforces the oscillatory behavior of the first harmonic mode, much like increasing the first harmonic gain $\left(\mathrm{K}_{1}\right)$ while fundamental mode is steady. When rod reactivity is changed to $-10 \phi$, fundamental mode power decreases about $15 \%$ and the first harmonic oscillation is suppressed.

The contribution of the fundamental mode void reactivity feedback dominates at the end of Region II, because of the suppression of the first harmonic mode. Moreover, this fluctuation frequency is a signature of a different interaction. If pressure drop along the chimney is focused around this region, it's possible to see that these higher-frequency oscillations result from the changes in the void fraction. The spectrum of the fundamental mode power when $\mathrm{K}_{0}>0$ has a frequency resonance at $\omega=0.0161 \mathrm{rad} / \mathrm{sec} \cong 0.1 \mathrm{~Hz}$, a characteristic frequency for pressure-drop oscillations. Pressure drop oscillation is a double instability mode, in which Ledinegg-type instability and a compressible volume in a boiling system interact and produce a low-frequency oscillation.

The reason that those fluctuations did not appear before is that fundamental mode gain was zero. Setting it to a nonzero value carries the effect of void fluctuations to reactor kinetics and those effects are superimposed on fundamental mode power. At the beginning of Region III simulated control rod reactivity $\left(\rho_{r}\right)$ is set back to zero and this results in about $15 \%$ overshoot in the global power from the steady-state value.

\subsection{Region III}

Even though the Region III differs in the first harmonic mode gain set to its critical value from the Region II, the genuine distinction is that the out-of-phase oscillations are re-excited after they all die away. As can be seen in the top section of the Figure 19, the first harmonic power dies away around $268^{\text {th }}$ minute. The first harmonic gain is then set back to its critical value and kept the same. However, the large amplitude of the global power succeeds to enliven the first harmonic oscillations albeit the first harmonic gain is critical. 
As the power goes down after a 10 -cent reactivity insertion around $267.7^{\text {th }}$ minute for relatively long time the cross-mode interaction does not appear as effective as before. The big-amplitude, lowfrequency oscillations between 268.5 and $269^{\text {th }}$ minutes do not have high-frequency components because the first harmonic power died away. Since the power level is comparatively low, cross-mode excitation does not take place effectively as it did before despite the first harmonic gain is still critical.

Once the loop becomes unstable, the power control is handed back over to the host computer, and the system is shut down and secured. 


\subsubsection{Evaluation of BWR Stability Monitors}

The second goal of Phase 3 was to evaluate in-phase and out-of-phase BWR stability. The inphase oscillation is associated with the fundamental mode of neutron distribution. When in-phase oscillations occur, the local power change is consistent with the average power change. The out-ofphase instability is associated with the first harmonic mode of neutron distribution. In an out-of-phase event, the average power level may not fluctuate noticeably while half of the core oscillates out-ofphase of the other half.

\subsubsection{In-Phase Stability Monitor}

The first experiment was to evaluate an in-phase stability monitor. The setup is illustrated schematically in Figure 21. In the setup, the real-time simulation of the thermal hydraulic phenomena in a boiling water reactor channel is coupled with the Penn TRIGA reactor forming a hybrid BWR reactor system. The measured reactor power signal drives the thermal hydraulic channel model, which computes the void reactivity feedback. The void reactivity feedback is realized by using the Experimental Changeable Reactivity Device (ECRD) to drive the TRIGA reactor. The Adjustable Gain Block is included for two purposes. First, it is used to introduce perturbation into the close loop system. Second, it is used to compensate for the ECRD dynamics, which is not inherent in the BWR dynamics. The stability monitor is an extended Kalman filter, which is based on a simplified linear thermal hydraulic model coupled with one-group nonlinear point kinetics model. Based on the measured reactor power and external reactivity input (set to zero in our tests), the filter makes realtime estimations of the feedback gain, decay ratio and oscillation frequency of the closed-loop system. 


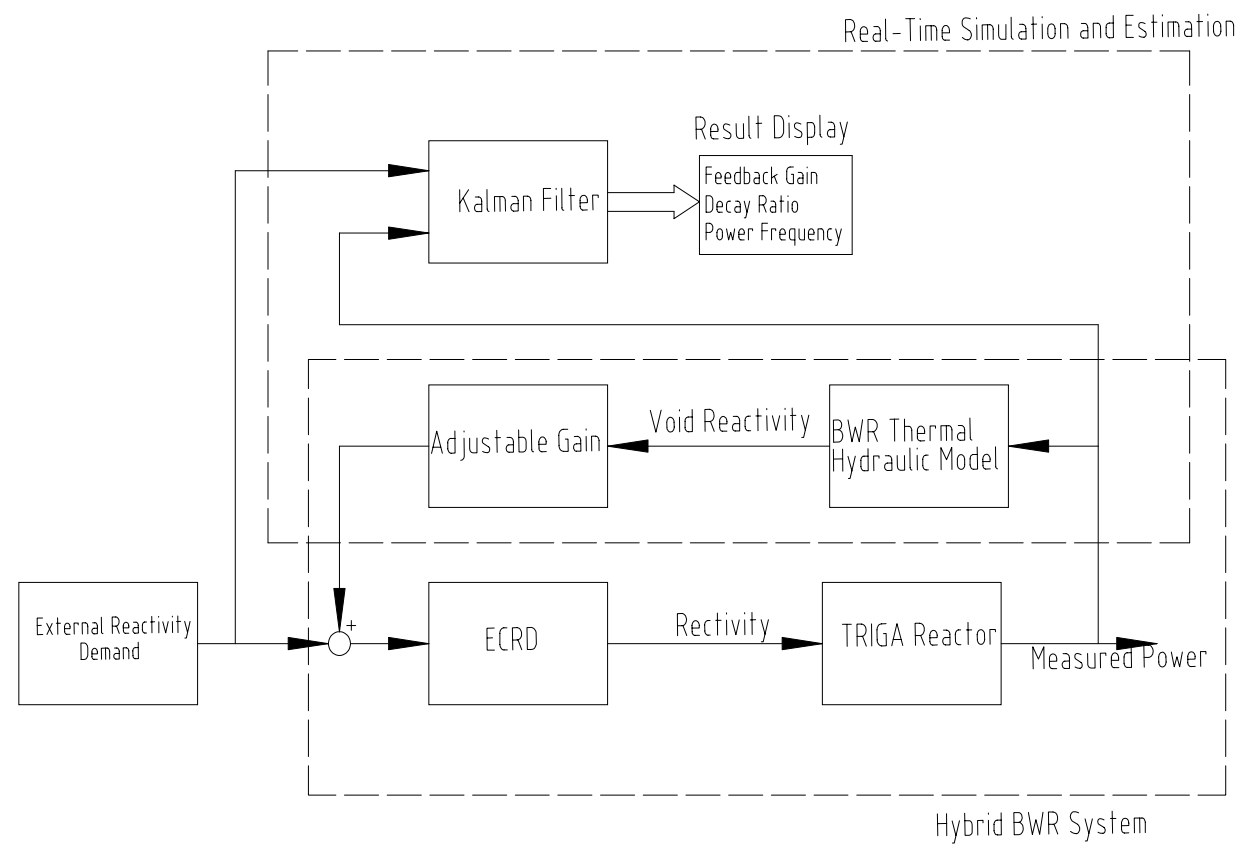

Figure 21. Setup for Testing the Core-Wide Stability Monitor

Some test results are presented in Figure 22. In the experiment, before the void feedback was introduced, the ECRD was properly positioned and the reactor was maintained at a steady operation level with the main control rod system of the TRIGA reactor. The void feedback loop was closed at about 20 seconds. From top to bottom, the figure gives the history of the adjustable gain change, measured reactor power, the estimated feedback gain, closed-loop decay ratio and corresponding frequency. The estimated decay ratio gives a direct indication how far the system is from its stable condition. From the figure, the estimated decay ratio was close to 1.0 except during some transition periods. The estimated decay ratio is confirmed by the measured reactor power, which shows that the BWR hybrid system was approaching limit cycle. The transitions in the estimation are caused by the dynamic behavior of the Kalman filter. The estimated frequency is close to $0.5 \mathrm{~Hz}$, which is close to the value obtained directly according to the measured reactor power. 

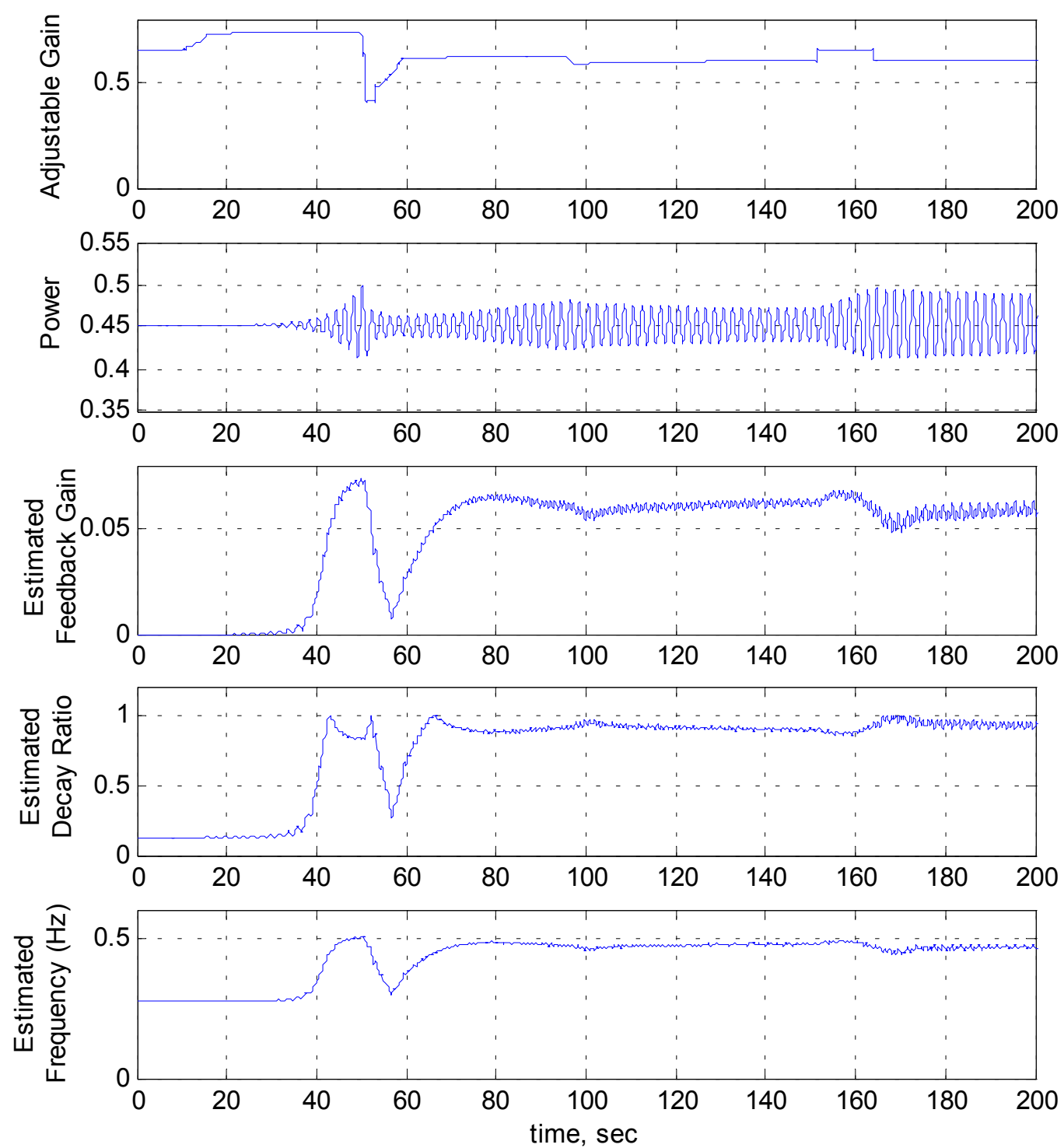

Figure 22: Results for In-Phase Stability Monitoring Experiments

Further work should be focused on two aspects. First, the above analysis shows that the estimator did not follow the plant very well when the plant experienced a fast transient. The Kalman filter design could be improved to get better performance. Secondly, the dynamics of the ECRD could be better determined so that its dynamics can be accounted for in the hybrid simulation and/or the stability monitor. 


\subsubsection{Out-of-Phase Stability Monitor}

The experimental setup for the implementation and testing of the out-of-phase stability monitor is schematically illustrated in Figure 23. The TRIGA reactor and the simulated first harmonic kinetics are used to approximate modal neutron kinetics. The thermal-hydraulic block consists of two boiling channels. One channel represents the fundamental mode and the other represents the harmonic mode. Each channel contributes to the system stability through its void reactivity feedback, and the channels interact through the two coupling modes of the neutron kinetics. Two Kalman filters are used respectively as instability monitors for the two types of instability events. The Kalman filters give the real-time estimation of the decay ratios, frequencies and void feedback gains for each mode.

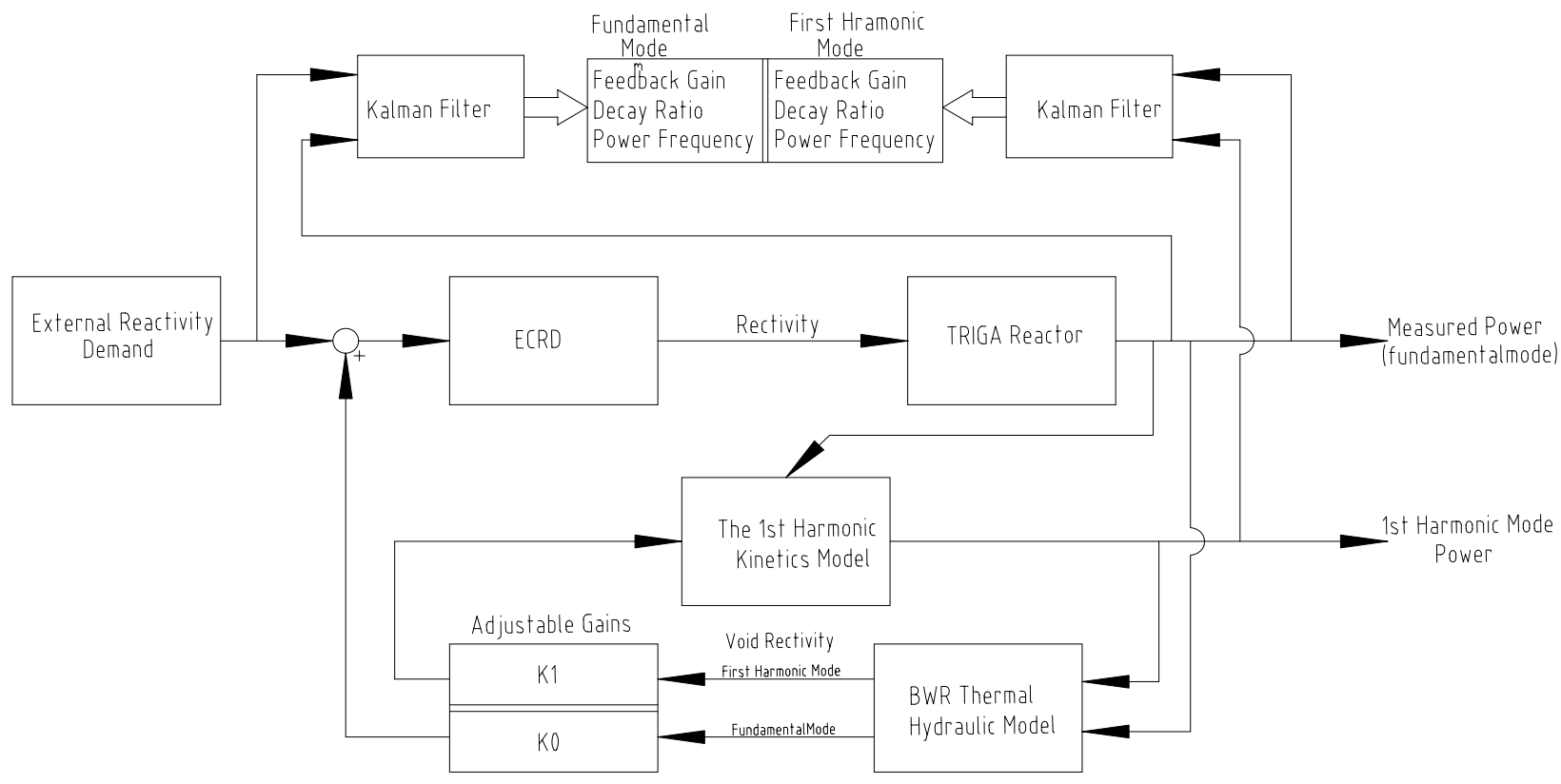

Figure 23. Setup for Testing In-Phase and Out-of-Phase Stability Monitors

Some experimental results are plotted in Figure 24. On the left are the results from the fundamental mode monitor. The results from the monitor for the first harmonic mode are shown on the right. According to the measured TRIGA power and the simulated output of the $1^{\text {st }}$ harmonic component, the filters give reasonable estimation of decay ratios and oscillation frequencies when the estimations converge. It also shows that the filter for the $1^{\text {st }}$ harmonic mode monitor shows a better 
response compared to the filter for the fundamental mode monitor. The fundamental mode monitor shows poor performance in following the plant and needs to be improved in the future work.
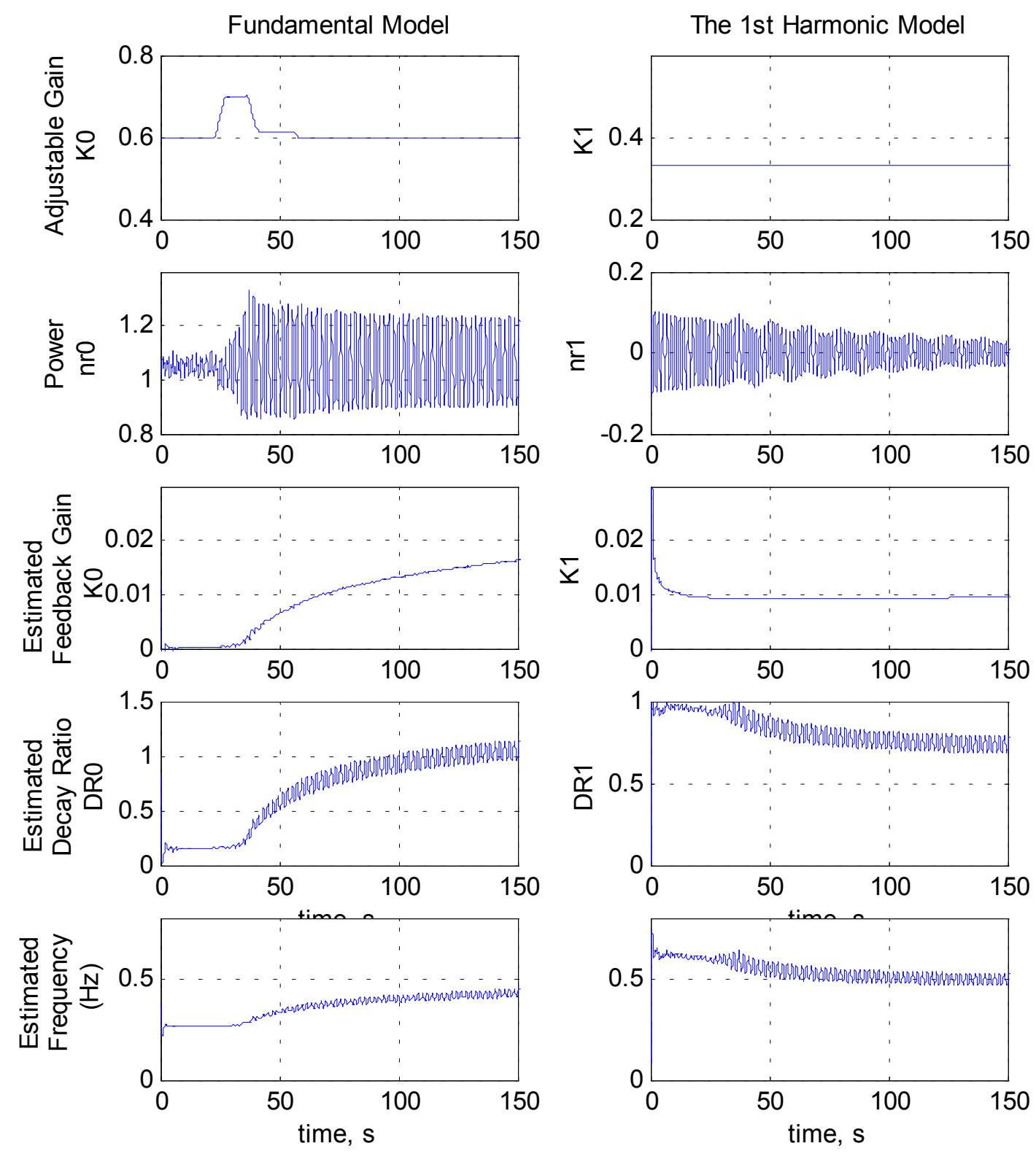

Figure 24. Results for Out-Phase Stability Monitoring Experiment 


\subsection{Phase 4}

Phase 4 was originally scheduled for the one-year period from July 1, 2001 to June 30, 2002. As explained in the request for the no cost extension, the project incurred an unforced change of scope through the failure of a major piece of experimental equipment. The recovery procedure described in the Appendix was completed in December 2002 and operation of the loop to complete Phase 4 was conducted until April 2003. At that time, another malfunction occurred where only 3 of the 12 electrically heated rods were available. Three-rod operation does not provide enough heat input to develop two-phase conditions in a reasonable time due to heat losses from the system. The Mechanical and Nuclear Engineering Department provided funds to have the bundle dismantled and rebuilt using professional engineering services. As of the end of September 2003, the reconstructed bundle is ready for reinstallation. Future operation of the loop is planed as part of the required senior nuclear-engineering laboratory course in Experiments in Reactor Physics.

The original phase 4 description is: Phase 4 will have a duration of 12 months. The goals of this phase are a) implement the hybrid reactor testloop simulator capability with optional modal kinetics and parallel boiling channel simulations b) design and implement flow control incorporating a jetpump for the SBWR testloop; c) develop wide-range automated control of BWR incorporating optimized-feedforward and robust feedback control; d) evaluate automated wide-range ABWR control in the hybrid simulation environment.

Phase 4 goal a) was concluded with the development of the computer hardware and software to implement the hybrid reactor testloop simulator. Phase 4 goal b), design and implementation of flow control, resulted in the addition of a motorized valve to restrict flow because the natural circulation driving force was found to be more than sufficient to provide cooling for the facility's power level. Dynamic manipulation of the valve position was sought to stabilize the flow. Phase 4 goal c) has been completed in the theses and publications of Shyu [23, 29, 51]. Phase 4 goal d) could not be completed within the one-year no-cost extension because of the malfunctions and repairs of the testloop. Furthermore, operation of the test-loop in a stable manner could not be reliability duplicated. However, goal c) included simulation validation for an ABWR.

\subsection{Additional Work Peformed}


During the periods when the loop when was unavailable, alternative supporting research was conducted in two areas: 1) the development of additional ABWR control approaches and 2) stability analysis of low-pressure two-phase systems. The additional ABWR control approaches include multivariable fuzzy-logic control (FLC) and fuzzy adapted recursive sliding mode control (FARSMC) in the MS Thesis and PhD dissertation of Huang [24, 25, 44, 48, 50, 55]. The adaptation of these advanced control techniques for the desired experimental validation in the HRLS is still hampered by the inability to reliability operate the loop in a stable manner; thus, a major effort was initiated to develop stability analysis of the testloop, which is expected to lead to another dissertation. The goal of stability analysis is to identify facility and procedure modifications to obtain more predictable stable operation. The remainder of this section presents some initial results of the stability methodology development.

\subsubsection{Thermal-Hydraulic Instabilities of Low Pressure Two-Phase Flow.}

Thermal-hydraulic instability of two-phase flow has attracted a lot attention since early days in the history of developing boiling reactors because of its importance to reactor operation and safety. In an early work by Fukuda et al [9], thermal-hydraulic instabilities for both natural and forced twophase circulation were classified into two major categories: Type-I and Type-II, which has been generally accepted. Gravity effects dominate in Type-I instabilities, especially for a system with a long unheated riser at low coolant qualities. This type of instability is of specific importance for natural circulation boiling water reactors. On the other hand, frictional pressure drop is dominant in Type-II instabilities, which tend to occur at relatively high power and high quality. The Type-II instabilities first received major attention and have been investigated extensively since Type-II instabilities have been a major concern in a conventional BWR. Reference [7] includes a thorough review of the research work in this area. Since the early 1990's with the development of SBWR, research activities in Type-I instabilities have become very active. This activity is because a simplified boiling reactor is susceptible to Type-I instabilities when it starts from low pressure and low temperature conditions, as originally pointed out by Aritomi et al. [10]

A number of low-pressure natural circulation test facilities have been constructed to study thermal hydraulic instabilities that could occur in a SBWR during start-up process. [11-16]. 


\subsubsection{Guysering Instability}

The instabilities are classified into two major categories: guysering instabilities and instabilities induced by void flashing. The instabilities induced by void flashing are of Type-I instabilities. The term "instabilities induced by void flashing" is used to emphasize the important role of void flashing in Type-I instabilities encountered in a low-pressure two-phase natural circulation system with a long unheated riser.

Under certain thermal-hydraulic conditions, guysering instabilities can occur in a two-phase natural circulation loop at low pressure and low power. Fundamental studies in the area of guysering instability have been conducted by Aritomi et. al. [10] and Wang et. al.[17]. Experimental and numerical studies were carried out by Rao et. al. [18] to investigate the mechanism of guysering. A thermal hydraulics computer code was developed by Paniagua et. al. [19] to simulate geysering phenomina in a natural circulation system starting from subcooled conditions. The performance of the code was evaluated with the experimental results by Wang et. al. [17] Based on the studies and observations of these researchers, the process of guysering, its mechanism and the effect of various system parameters on guysering will be discussed.

The guysering process can be described as follows. Voids are generated in the heated channel section. As voids move upward at low system pressure, they grow due to the decrease in hydrostatic pressure head and can cover most of the cross section of the channel. Large bubbles are then condensed in the riser or upper plenum, where the fluid is still subcooled. With the bubbles collapse and subsequent decrease in pressure, the subcooled liquid reenters the channel and restores the nonboiling condition. When the condensation rate of bubbles is greater than the circulation flow, flow reversal can take place. This process repeats periodically and causes flow oscillations. Therefore, bubble formation, growth, and collapse phenomena are crucial in the occurrence of guysering instability. It is clear two conditions are necessary for the occurrence of guysering: formation of large bubbles in the heated section and subcooled condition at the inlet of the riser or the upper plenum.

Different forms of guysering have been observed on different test facilities. Periodic oscillations due to guysering were observed by Aritomi et. al. [10] and Rao et. al. [18] in the experiments conducted on their test facililities. Wang et. al. reported a quasi-periodic type of 
oscillations due to guysering: three oscillations followed another oscillation of larger magnitude. [17] This type of oscillation was also predicted numerically by Paniagua et. al. [19] In contrast, flow oscillations due to guysering observed by Jiang et. al [20] behaved in a manner of random pulses. These types of flow oscillation are shown in Figure 25.

The characteristics (oscillation amplitude and frequency) of guysering are affected by various system parameters such as system geometry, pressure, inlet subcooling at the core inlet and etc. At a given heating power level, guysering is sensitive to system pressure and inlet subcooling. Specifically, an increase in system pressure tends to suppress guysering and reduce oscillation amplitude. $[18,19]$ Moreover, it is found that guysering disappears when system pressure is beyond a certain value. In his study, Paniagua concluded that the threshold value is about 0.3 Mpa.[19] Jiang et. al. also found that guysering disappears in the facility they worked when the facility is started up at the system pressure greater than 0.3 Mpa. [20] The reason for stabilization is that an increase in pressure can suppress the formation of large bubbles and is confirmed by the study by Chiang et al [11]. In his study, Chiang investigated the effect of pressure on flow regimes. It is found that the large bubbly flow region becomes rather small at $0.2 \mathrm{Mpa}$ compared to $0.1 \mathrm{Mpa}$ (the pressure of the facility used was limited to $0.2 \mathrm{Mpa}$ ). Similarly, a decrease in inlet subcooling tends to suppress guyering and guysering disappears when the inlet subcooling is low enough that the liquid at inlet of riser reaches its saturation temperature. [18, 19] 


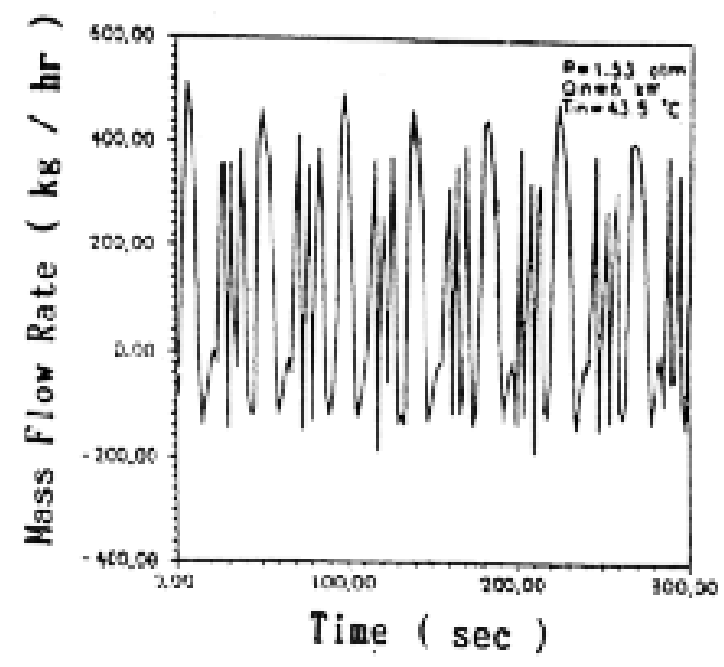

a). Wang et al.

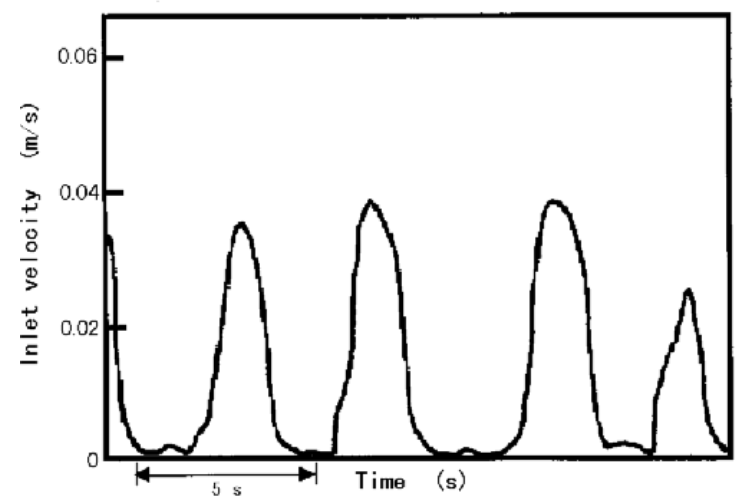

b). by Rao

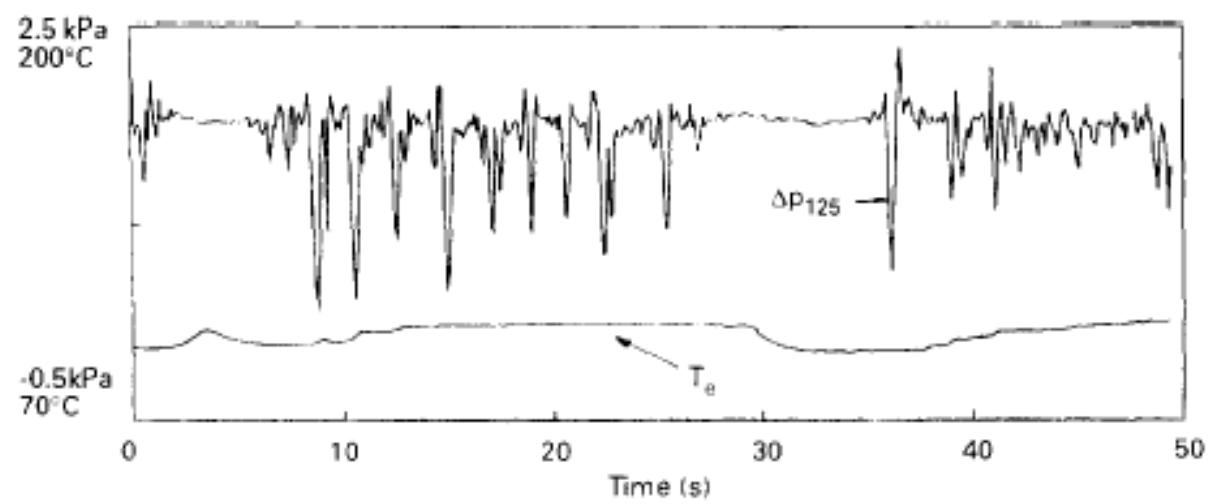

c). by Jiang

Figure 25. Guysering Instabilities 


\subsubsection{Instabilities induced by Void Flashing}

The other type of instability at low-power and low-pressure conditions is related to void flashing in the unheated riser section. An extensive study of flashing-induced instabilities has been conducted in the last decade. Manera et. al. provides a detailed description of the characteristics flashing-induced instabilities and gives an informative analysis of the mechanism of flashing-induced instabilities. [14] The flashing-instabilities are classified as intermittent natural circulation and unstable two-phase circulation. Similar instabilities were also observed by J.H. Chiang et. al. and were called natural circulation oscillation in his work. [11] Inada et. al investigated the mechanism of flashing-induced instabilities analytically. [13] Figure 26 shows the flashing-induced instabilities at the pressure of 0.1 bar and different inlet temperatures observed by Manera et. al. Figure 26a and Figure $26 \mathrm{~h}$ represent stable single-phase and two-phase situations respectively. The figures from $26 \mathrm{~b}$ to $26 \mathrm{f}$ present the time series of circulation flow rates corresponding to intermittent natural circulation. The intermittent natural circulation is characterized by an alternate presence of liquid and two-phase mixture in the riser section. At the given power and system pressure, oscillation period decreases as inlet temperature increases. Figure $26 \mathrm{~g}$ shows the case of unstable two-phase natural circulation, where two-phase mixture is always present in the riser section due to flashing, but the flashing start point fluctuates.
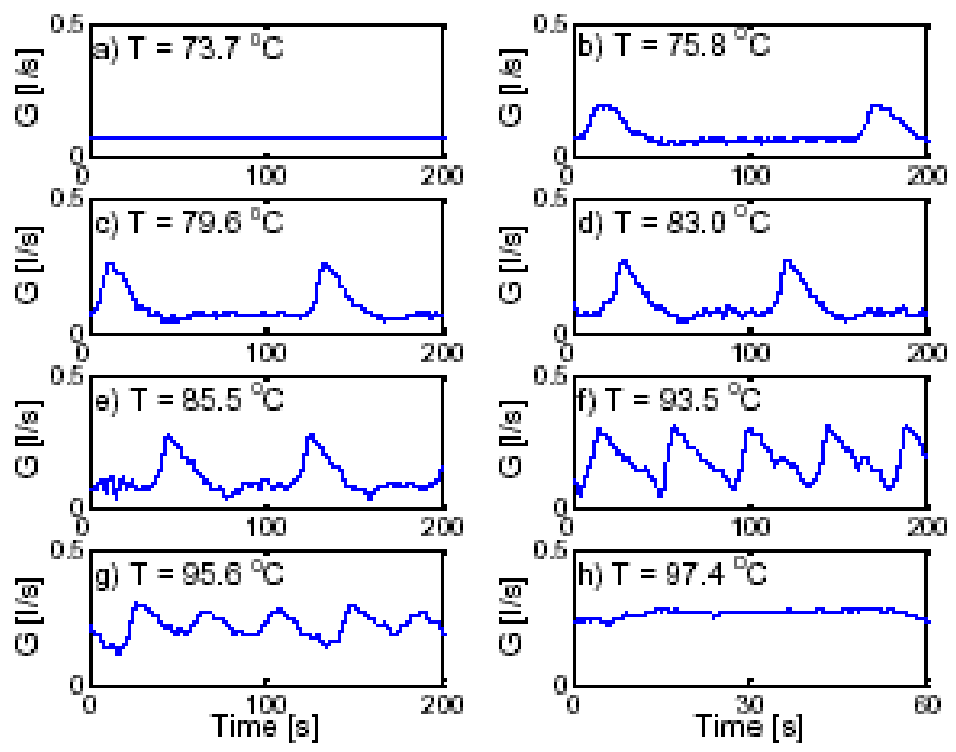

Figure 26. by Manera et. al 
For a low-pressure natural circulation system with a long unheated riser, void flashing in the riser can be dominant in determining the thermal-hydraulic stability. This is evident according to the references 11, 14, 20,21. The void flashing can be described as the following. As the coolant flows through the heated section, its temperature is increased but may not reach saturation conditions at the exit of the heated section. The coolant leaving the heated section flows upward in the riser. Along the riser, saturation temperature decreases due to the decrease of pressure head. Thus void generation can start at some location in the riser if the liquid temperature at the exit of the heated section is higher than the saturation temperature with respect to the pressure at the exit of the riser. Void flashing increases the buoyancy of the natural circulation loop and leads to an increase in circulation flow rate. Increased flow rate in turn causes the decrease in coolant temperature at the exit of the heated section, which will suppress the flashing in the riser. The flow rate will then decrease and consequently a new flashing cycle starts. This is a very general description of flashing-induced oscillation. However, flashing-induced instability phenomena are complicated and there are different views about their nature. For example, Manera et. al. [14] points out that void flashing is a nonequilibrium process and void flashing fronts develop both downward and upward in the riser while Jiang regards void flashing as a thermal equilibrium process and void flashing starts at the exit of the riser and develops downward.[20,21] Another issue concerns the relation between density wave stability and flashing-induced stabilities. Chiang [11] suggests that flashing-induced oscillations are similar to density wave oscillations but a different type of instability. Manera et. al. classifies flashing instabilities as a type of density wave instability. [14] Inada et. al. thinks that it is still an open question whether the flashing-induced stabilities should be called density wave oscillation or enthalpy wave oscillation. [13]

Although there are different views about the nature of flashing-induced instability phenomena, the features of flashing-induced phenomena are summarized as follows:

1). The characteristics of the oscillations are dependent on the transportation of enthalpy.

2). The temperature oscillations at the chimney inlet and outlet are $180^{\circ}$ out of phase.

3). Increasing system pressure and inlet temperature of the heated section tend to suppress flashing-induced instabilities.

4). The condition for the occurrence of void flashing is the liquid temperature at the exit of heated section is greater than the saturation temperature with respect to the pressure at the exit of the riser. 


\subsubsection{Stability Map}

An operation point of a natural circulation system is completely defined by three parameters: system pressure, inlet subcooling (of the heated section) and power. A subcooling vs. power plane with stability boundaries is often used to represent the stability map of a natural circulation loop corresponding to a given system pressure. As an alternative approach, the operation point can also be defined with two non-dimesional variables: subcooling number and phase change number. Recently, the first type of stability map has been more often used by researchers in reporting their work. In the following, the stability map represented in the subcooling vs. power plane will be used in discussing the stability characteristics of low-pressure natural circulation systems.

At low pressures, a natural circulation loop typically has three operation ranges: single-phase stable region, two-phase unstable region and two-phase stable region, even though two-phase stable operation might not be easily achieved. Figure 27 shows the stability maps of a natural circulation test facility at two different system pressures reported by Inada et. al. [13] The test facility investigated by Inada is a scaled version of a typical natural circulation SBWR. The test facility has a subcooler and a pre-heater so that experiments can be conducted in a wide range of inlet subcooling conditions. The stability map in Figure 27 a corresponds the case of $p=0.1 \mathrm{Mpa}$ and the one in Figure $27 \mathrm{~b}$ corresponds to the case of $\mathrm{p}=0.2 \mathrm{Mpa}$. The solid lines represent stability boundaries analytically obtained by the authors. According to the figures, fluid can even enter the heated section as twophase mixture. Even though the two stability maps were obtained from a specific test facility, they reveal some general features expected of low-pressure natural circulation loops, including:

1). When inlet subcooling is large and the whole loop is in single-phase status, stable singlephase natural circulation is achieved.

2). When inlet subcooling is reduced so that the conditions for void flashing are reached, intermittent oscillation occurs. No guysering was reported by Inada [12,13]. Guysering could occur around the upper stability boundary as shown in Figure 27aa or Figure 27b.

3). With inlet subcooling low enough, void always appears in the riser and two-phase instability occurs.

4). As inlet subcooling is further reduced, stable two-phase circulation may be achieved. However, it is obvious that stable two-phase region is very small if the inlet fluid is maintained subcooled. For some test facilities, due to heat loss along the loop, it may not be easy to maintain inlet subcooling low enough for two-phase stability.

5). The lower stability boundary is affected by power rate to a very small degree. 


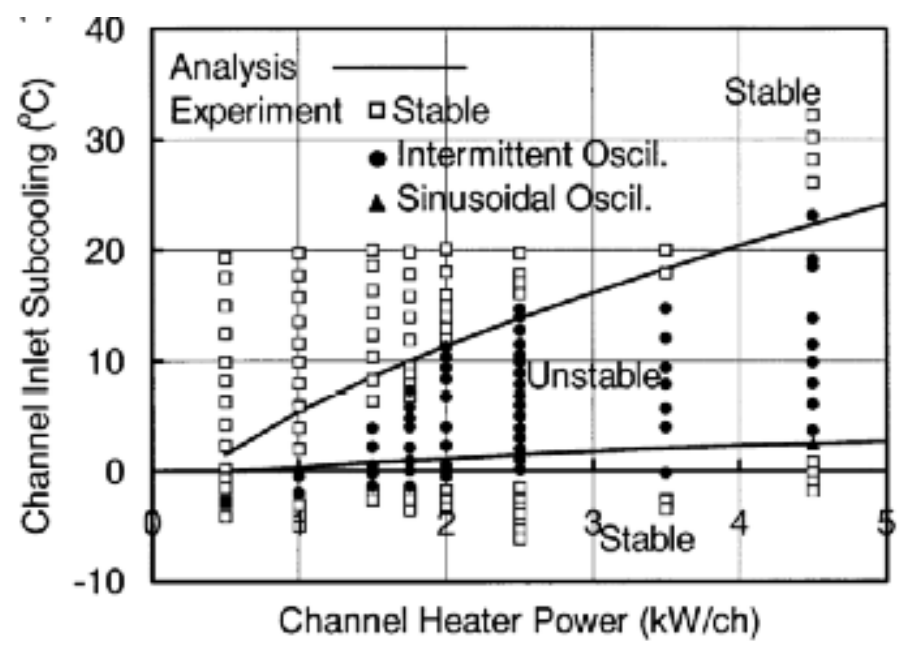

(a) $\mathrm{p}=0.1 \mathrm{Mpa}$

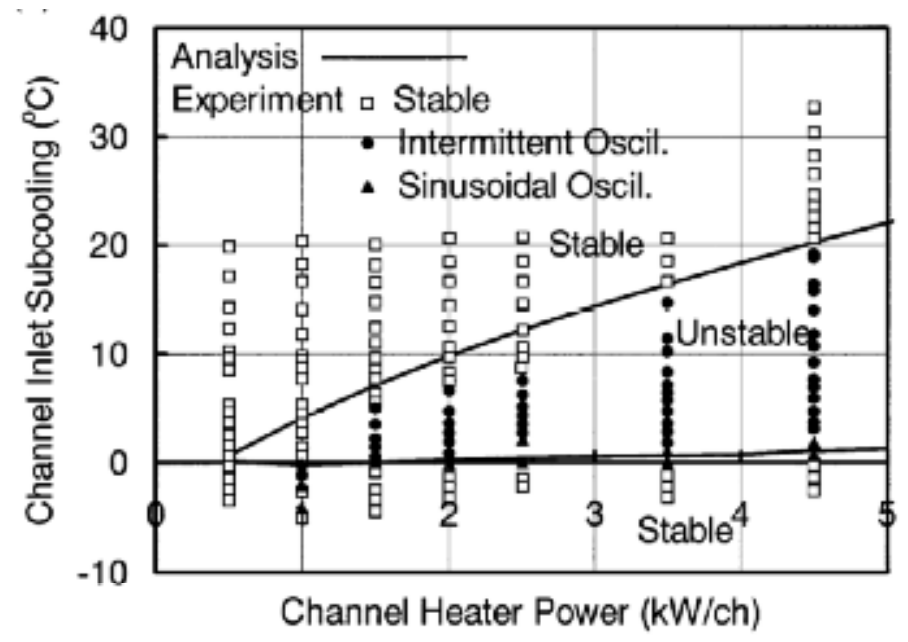

(b) $\mathrm{p}=0.2 \mathrm{Mpa}$

Figure 27. Stability Map of Natural Circulation Tesr

The discussion in the prior section shows that an increased pressure tends to suppress all types of instabilities. However, the effect of the system pressure is hardly seen in Figure 27. Figure 28 gives two stability maps obtained by Manera et al. [14]. Figure 28a corresponds to the case of $\mathrm{p}=0.1 \mathrm{Mpa}$ and Figure $28 \mathrm{~b}$ corresponds to the case of $\mathrm{p}=0.2 \mathrm{Mpa}$. It is evident that the stability maps shown in Figure 28 are similar to those shown in Figure 27. From Figure 28, the effect of system pressure is more clear: an increase in system pressure will extend the stable two-phase region. The influence of the system pressure may be more obvious from the study of Jiang et al. [20, 6] His studies were conducted on a test loop, which was constructed to investigate the thermal hydraulics of a low-temperature natural circulation nuclear heating reactor. In his work, Jiang reported a stability map at low-pressure 
conditions $(\mathrm{p}=0.1 \mathrm{Mpa})$ and a stability map at normal operation pressure $(\mathrm{p}=1.5 \mathrm{Mpa})$. It shows that it was difficult for the test facility to achieve stable two-phase operation at low-pressure conditions while the facility was able to operate in stable two-phase mode at its nominal operation pressure.
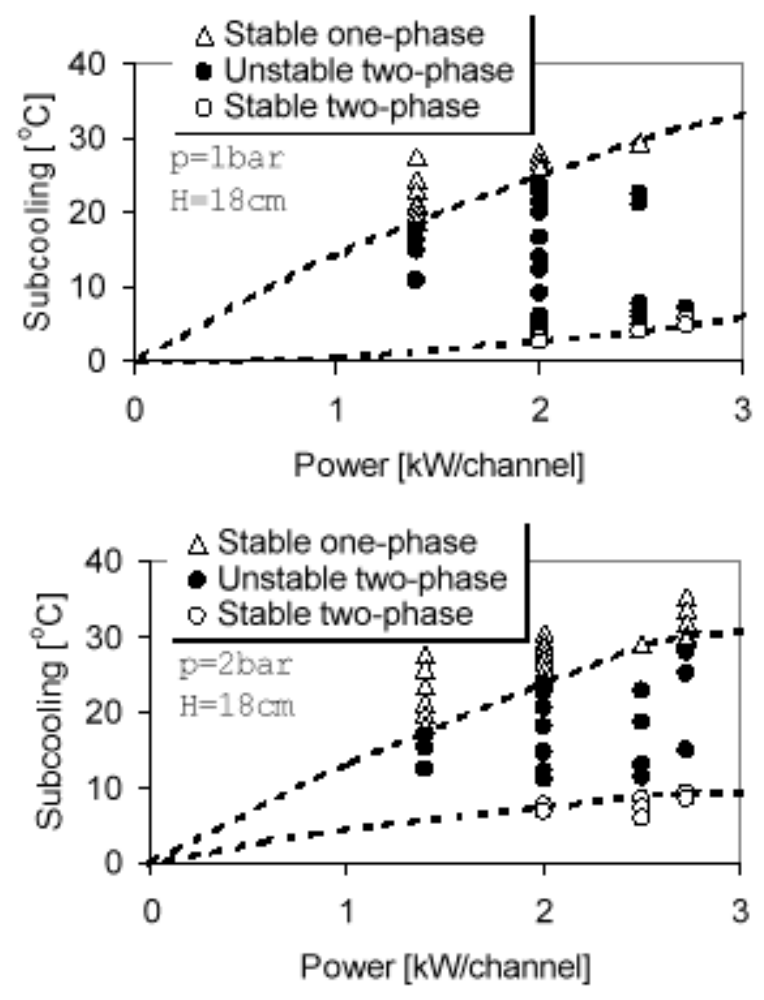

Figure 28. Stability Maps by Manera

One important objective in the study of the thermal-hydraulic behaviors of two-phase natural circulation at low-pressure and low-power rate conditions is to investigate possible thermal-hydraulic instabilities that may be encountered during the start-up mode of the SBWR and to develop proper start-up procedures. The startup of the SBWR is a process of increasing pressure, temperature and establishing circulation flow of the coolant system with heat generated from nuclear fission. In this process, the reactor power rate is increased, the coolant system realizes the transition from singlephase to two-phase natural circulation, and the system pressure is established by the void generation. During this process, the occurrence of thermal-hydraulic instabilities is unacceptable. It was originally pointed out by Aritomi et al that thermal-hydraulic instabilities could occur in the SBWR at low-pressure and low-power conditions during start-up process. [10] Chiang proposed three types of start-up procedures for further investigation. [11] Jiang showed that stable transition from singlephase to two-phase is impossible if the test facility was started from atmospheric pressure. [20] In his 
work, Jiang detailed a three-step start-up procedure applied to the test loop that he investigated. Experimental studies conducted on the DANTON facility by Manera et. al. also showed that the pressure increase due to void generation in the coolant system is not sufficient to suppress completely flow oscillations if the system is started at atmospheric pressure. [15]

\subsubsection{Dynamics of the Penn State Low-Pressure Integral Test Facility}

The thermal-hydraulic behavior of the LPITF has been studied experimentally. Both guysering type of instability and two-phase instability were observed. Figure 29 shows a time series of the circulation flow obtained in an experiment, which represents the type of two-phase natural circulation oscillation. It needs to be pointed out that the water level in the downcomer also oscillated with the circulation flow. The effect of the oscillation in water level is unclear. Effort was made to experimentally determine the conditions for stable two-phase natural circulation. Unfortunately, it was found that it was difficult for the system to operate in a stable manner. This behavior of the facility could be explained as follows:

1). A natural circulation system like the LPITF typically has a small stable two-phase operation region, which corresponds to low inlet subcoolings.

2). The inlet temperature of the LPITF cannot be effectively regulated since the system does not have a pre-heater or pre-cooler in the downcomer.

3). The diameter of the downcomer of the LPITF is relatively small (1.5") compared to the diameter of the riser (3"). Therefore, the water level in the downcomer is sensitive to the circulation flow rate.

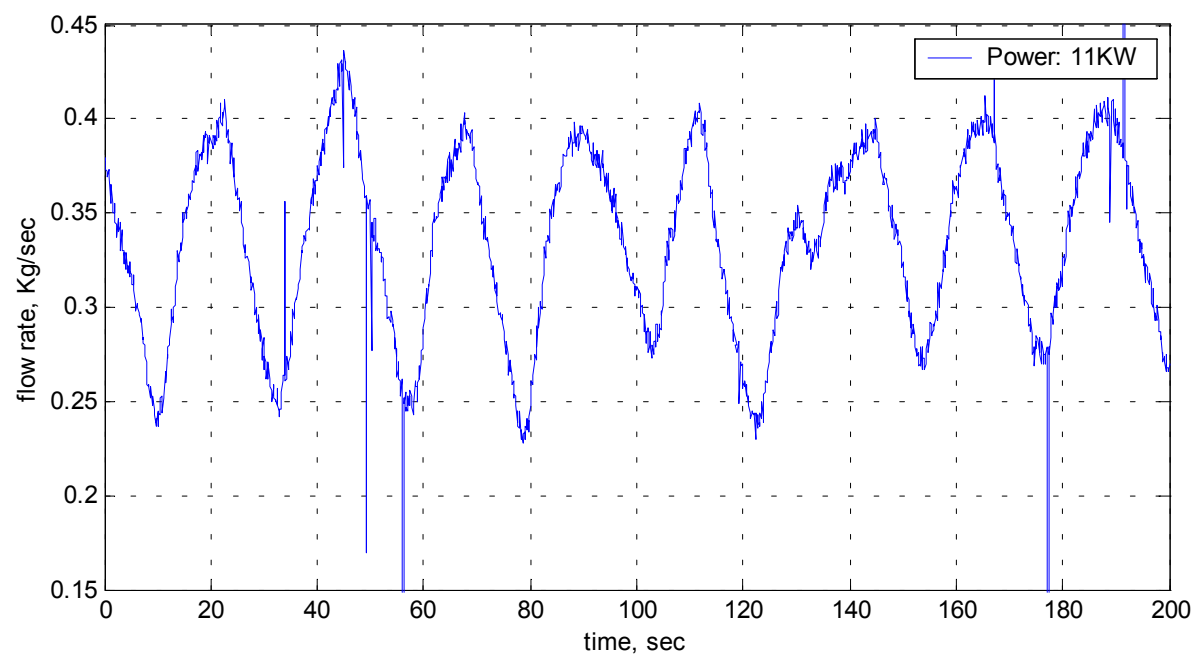

Figure 29. Two-Phase Natural Circulation Oscillation (the LPITF)

\subsubsection{Linear Stability Analysis}


The derivation of a linear stability model starts with the nonlinear partial differential conservation equations that govern two-phase flow dynamics. The time-domain linear conservation equations are derived by applying the first order perturbation of the nonlinear conservation equations and related constitutive equations around a given steady-state operating point. The resulting linear models are further Laplace transformed and frequency domain analysis are used for stability analysis.

With the above assumptions, the governing equations, namely, mass conservation, energy conversation, and momentum conservation, are given for the heated core section and the riser section as follows.

\section{Mass Conservation}

$$
A \frac{\partial}{\partial t}\left(\rho_{m}\right)+\frac{\partial}{\partial z}\left(w_{m}\right)=0
$$

where

$$
\begin{aligned}
& \rho_{m}=\alpha \rho_{\mathrm{f}}+(1-\alpha) \rho_{\mathrm{g}} \\
& w_{m}=\left\{\alpha \rho_{\mathrm{f}}+(1-\alpha) \rho_{\mathrm{g}}\right\} \cdot j_{m}
\end{aligned}
$$

\section{Energy Conservation}

$$
A \frac{\partial}{\partial t}\left(\rho_{m} h_{m}\right)+\frac{\partial}{\partial z}\left(w_{m} h_{m}\right)-q_{l}^{\prime}=0
$$

where

$$
h_{m}=(1-x) h_{\mathrm{f}}+x h_{\mathrm{g}}
$$

The equilibrium quality is defined as

$$
x=\frac{h_{m}-h_{\mathrm{f}}}{h_{\mathrm{g}}-h_{\mathrm{f}}}=\frac{h_{m}-h_{\mathrm{f}}}{h_{\mathrm{gf}}}
$$

For HEM two-phase flow model, the void and the equilibrium quality have the following relation,

$$
\alpha=\frac{1}{1+\frac{1-x}{x} \frac{\rho_{\mathrm{g}}}{\rho_{\mathrm{f}}}}
$$




$$
x=\frac{1}{1+\frac{1-\alpha}{\alpha} \frac{\rho_{\mathrm{f}}}{\rho_{\mathrm{g}}}}
$$

\section{Momentum Conservation}

$$
\begin{aligned}
\frac{\partial}{\partial t}\left(w_{m}\right)+\frac{\partial}{\partial z}\left(\frac{w_{m}^{2}}{A \rho_{m}^{+}}\right)+\rho_{m} g A \cdot \cos \theta+\frac{f}{D_{H}} \phi_{l o}^{2} \frac{w_{m}^{2}}{2 A \rho_{\mathrm{f}}} \\
+\sum_{i}\left\{\left(K \cdot \phi_{l o}^{2}\right)_{i} \frac{w^{2}}{2 A_{i} \rho_{f}} \delta\left(z_{i}-z\right)\right\}+A \frac{\partial p}{\partial z}=0
\end{aligned}
$$

The dynamic density is defined as follows [6],

$$
\frac{1}{\rho_{m}^{+}}=\frac{x^{2}}{\rho_{\mathrm{g}} \alpha}+\frac{(1-x)^{2}}{\rho_{\mathrm{f}}(1-\alpha)}
$$

It can be shown that the dynamic density is equal to the mixture density for HEM flow, which is

$$
\begin{aligned}
& \rho_{m}^{+}=\rho_{m} \\
& \frac{1}{\rho_{m}^{+}}=\frac{x}{\rho_{\mathrm{g}}}+\frac{1-x}{\rho_{\mathrm{f}}}
\end{aligned}
$$

The friction multiplier $\phi_{l o}^{2}$ in the HEM model is evaluated with the following equation,

$$
\phi_{l o}^{2}=\left[1+x\left(\frac{\rho_{\mathrm{f}}}{\rho_{\mathrm{g}}}-1\right)\right]
$$

$f$ is equal to the fiction factor for liquid single-phase flow at the same mass flux as the two-phase mixture mass flux. The fiction factor, $f$, is evaluated for turbulent flow as,

$$
f=0.316 \mathrm{Re}^{-.025}
$$

for $\operatorname{Re}<30000$. The Reynolds number is

$$
\operatorname{Re}=\frac{w_{m} D_{H}}{\mu_{\mathrm{f}} A}
$$

$\mu_{\mathrm{f}}$ is the dynamic viscosity of the saturated water.

The fifth term in the momentum equation represents the form pressure drop through the spacers. $\mathrm{Z}_{i}$ represents the location of spacer $i$. The delta function is defined as 


$$
\delta\left(z_{i}-z\right)= \begin{cases}0 & z \neq z_{i} \\ 1 & z=z_{i}\end{cases}
$$

The conservation equations given above are in partial differential equation forms. and are converted into ordinary differential equations by using a nodalization technique organized as shown in Figure 30. A single-node single-phase downcomer is not shown.

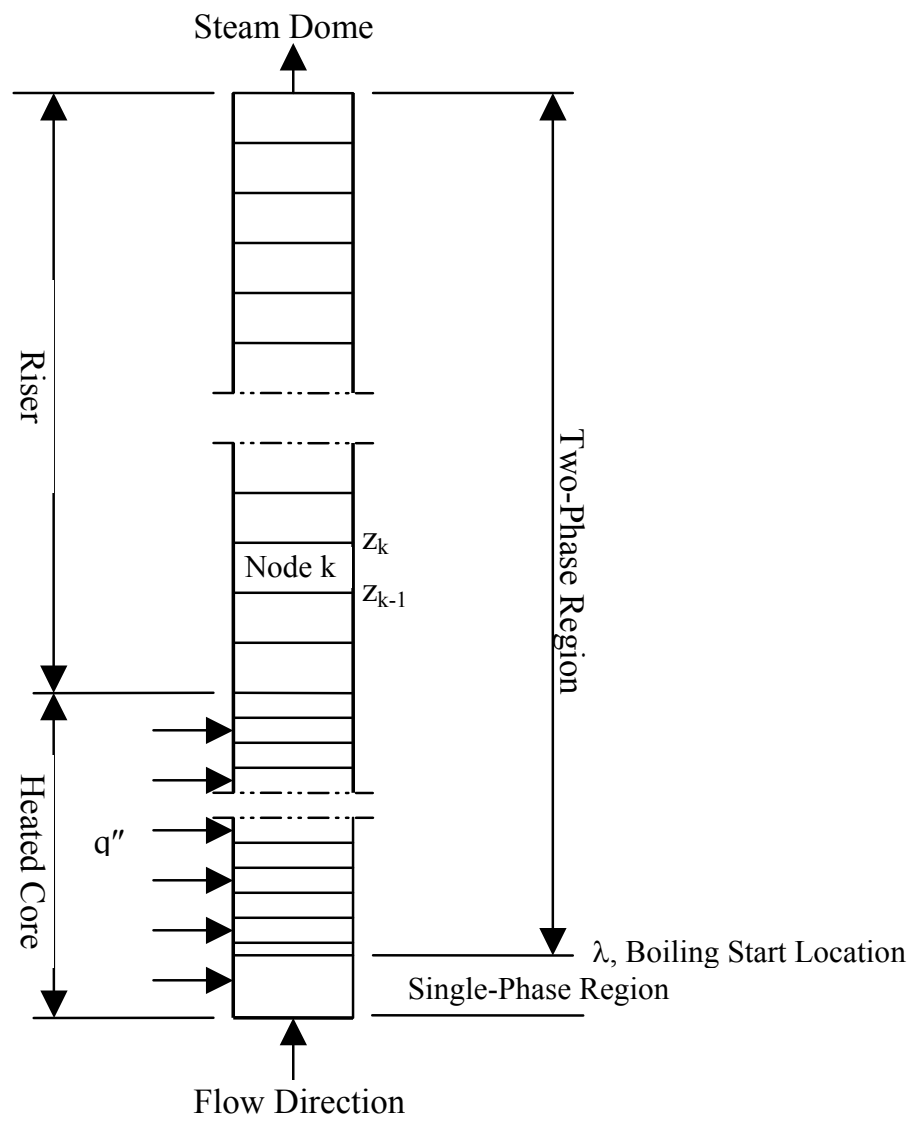

Figure 30. Nodalization of the Two-Phase Region

In order to perform linear stability analysis in the frequency domain, the nodal conservation equations are linearized and Laplace transformed. The $1^{\text {st }}$-order perturbation technique is used to linearize the nodal conservation equations about a steady-state operating point. The resulting linear equation groups are further Laplace transformed, converting the system from the time domain description to the frequency domain description. 
Each node is seen as a Multiple Input Multiple Output linear system. As shown in Figure 31, the inputs and outputs of each node are the enthalpy perturbation, the flow rate perturbation, and the pressure perturbation at its inlet boundary (lower boundary) and at its outlet boundary (upper boundary) respectively. It is also observed that the outputs of a node are the inputs of its downstream neighboring node.

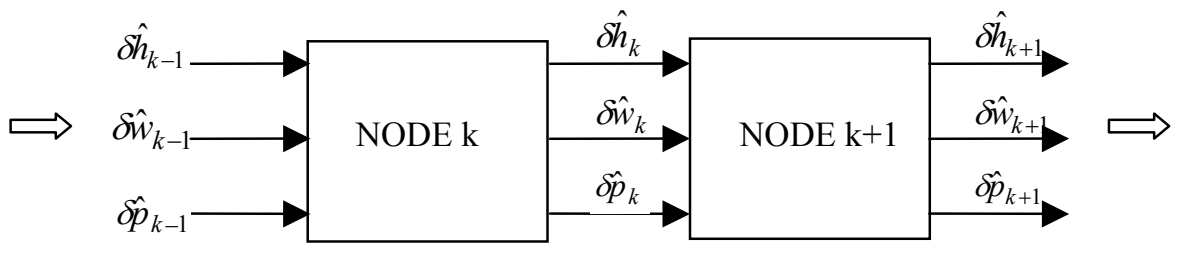

Figure 31. Linear System of Two Two-Phase Nodes

It is noted that above the dowmcomer and the riser is the steam dome. It is clear that there is no pressure difference along the flow path from the inlet of the downcomer and to the exit of the riser, which is,

$$
\delta \Delta \hat{p}_{1 \phi}(s)+\delta \Delta \hat{p}_{2 \phi}(s)=0
$$

Where

$$
\begin{aligned}
& \delta \Delta \hat{p}_{2 \phi}(s)=\boldsymbol{G}_{2 \phi}(s) \cdot \delta \hat{j}_{i n}(s) \\
& \delta \Delta \hat{p}_{1 \phi}(s)=\boldsymbol{G}_{1 \phi}(s) \cdot \delta \hat{j}_{i n}(s)
\end{aligned}
$$

Such relationship between $\hat{\delta}_{i n}(s)$ and $\delta \Delta \hat{p}_{2 \phi}(s)$ can be illustrated with the following feedback system: 


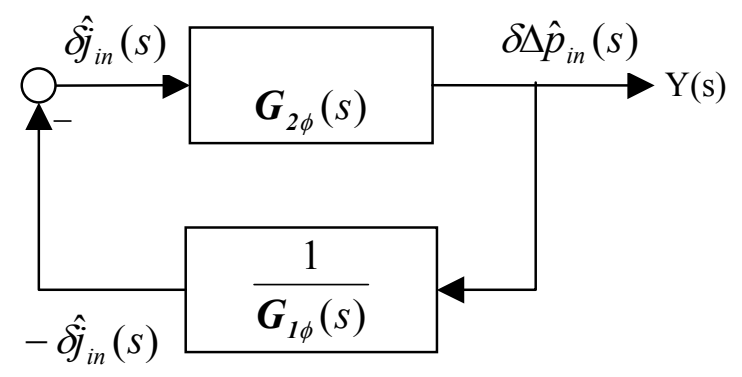

Figure 32. Linear Stability Analysis Model

In the above block diagram, the open loop transfer function is,

$$
\mathrm{GH}(s)=-\frac{\mathrm{G}_{2 \phi}(s)}{\mathrm{G}_{1 \phi}(s)}
$$

The stability of the closed-loop system illustrated in the block diagram can be determined by plotting the phase and magnitude of $\boldsymbol{G H}(j \omega)$, where $j=\sqrt{-1}$ and $\omega$ is angular frequency in $\mathrm{rad} / \mathrm{sec}$.

\subsubsection{Initial Stability Analysis Results}

The frequency response of the open loop transfer function is evaluated and the stability characteristics are determined by applying the Nyquist rule.

Figure 33 summarizes the algorithm that is implemented for the steady-state calculation and transfer function evaluation. The algorithm is implemented in the MATLAB environment. The MATLAB software is used in this work because it has efficient and robust algorithms for matrix evaluation. 


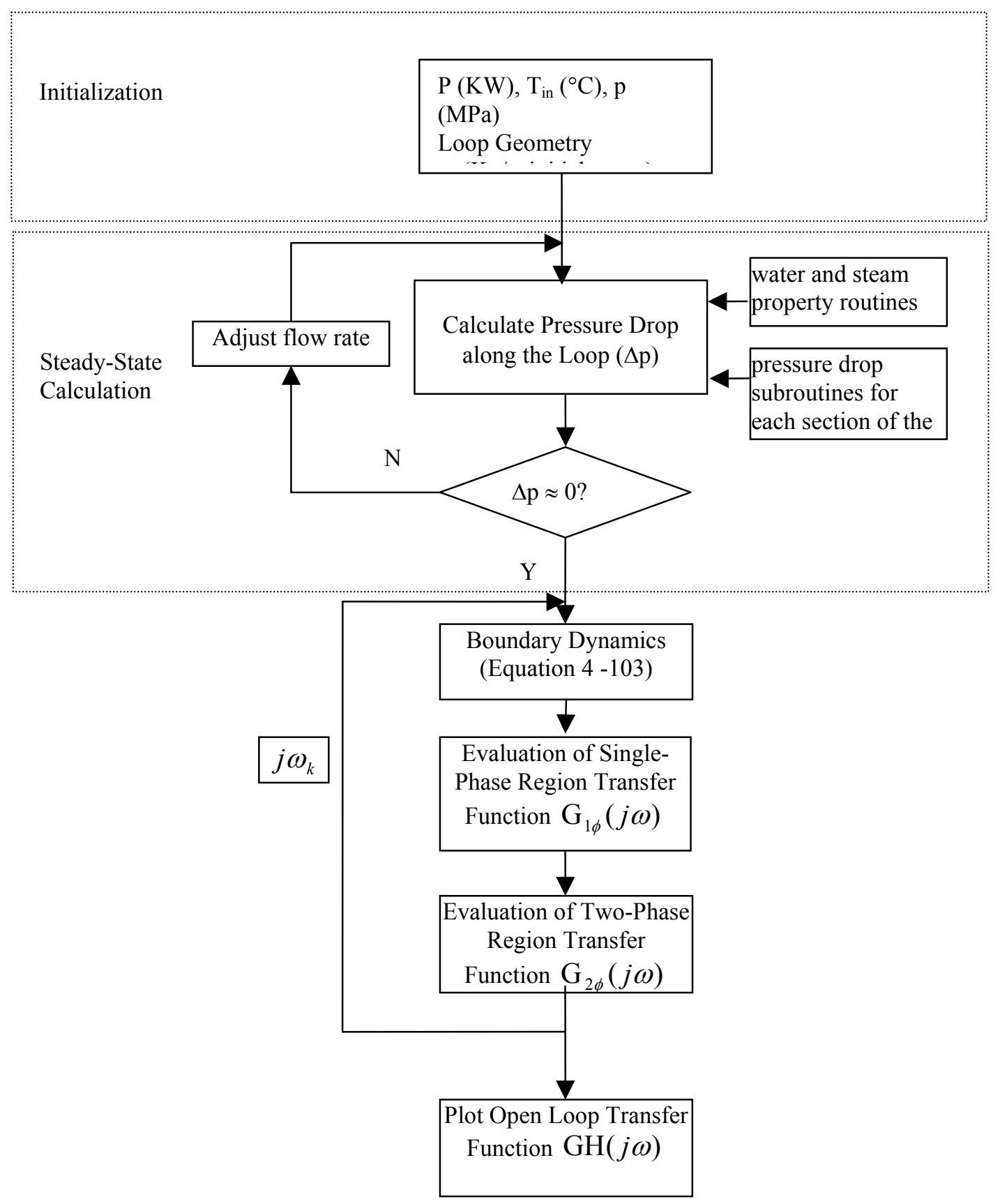

Figure 33. Stability Analysis Calculations

The diagram in Figure 33 mainly consists of three parts. The initialization provides the information of the operating condition, loop geometry and nodalization of the loop geometry. The state of the test loop is completely determined by the core inlet temperature, power input, steam domain pressure and the loop geometry. The searching of the steady-state operating point starts with 
guessing a mass flow rate. Given a flow rate value, the loop pressure drop can be calculated. If the loop pressure drop is not equal to zero. A new flow rate is generated according to the sign of the loop pressure drop. With the newly generated flow rate, the loop pressure drop is recalculated. This iteration process is carried out till a flow rate is found that the corresponding loop pressure drop is close to zero. In practice, the iteration process is finished with the loop pressure drop less than $10 \mathrm{~Pa}$.

Once the loop flow rate is determined, the pressure distribution, void distribution and quality distribution along the loop can be determined. The evaluation of the open loop transfer function, equation 27 , can be evaluated at each frequency point. The transfer functions $G_{1 \phi}(j \omega), G_{2 \phi}(j \omega)$ and $G H(j \omega)$, are subsequently evaluated as shown in the diagram. Finally, $G H(j \omega)$ is plotted in the complex plane for evaluating the stability characteristics of the test loop facility.

Figure 34 shows three Nyquist plots of the open loop transfer function for three different core inlet temperatures, namely, $99.5^{\circ} \mathrm{C}, 100^{\circ} \mathrm{C}$ and $100.5^{\circ} \mathrm{C}$. System pressure is $0.10 \mathrm{MPa}$ at $11 \mathrm{KW}$.

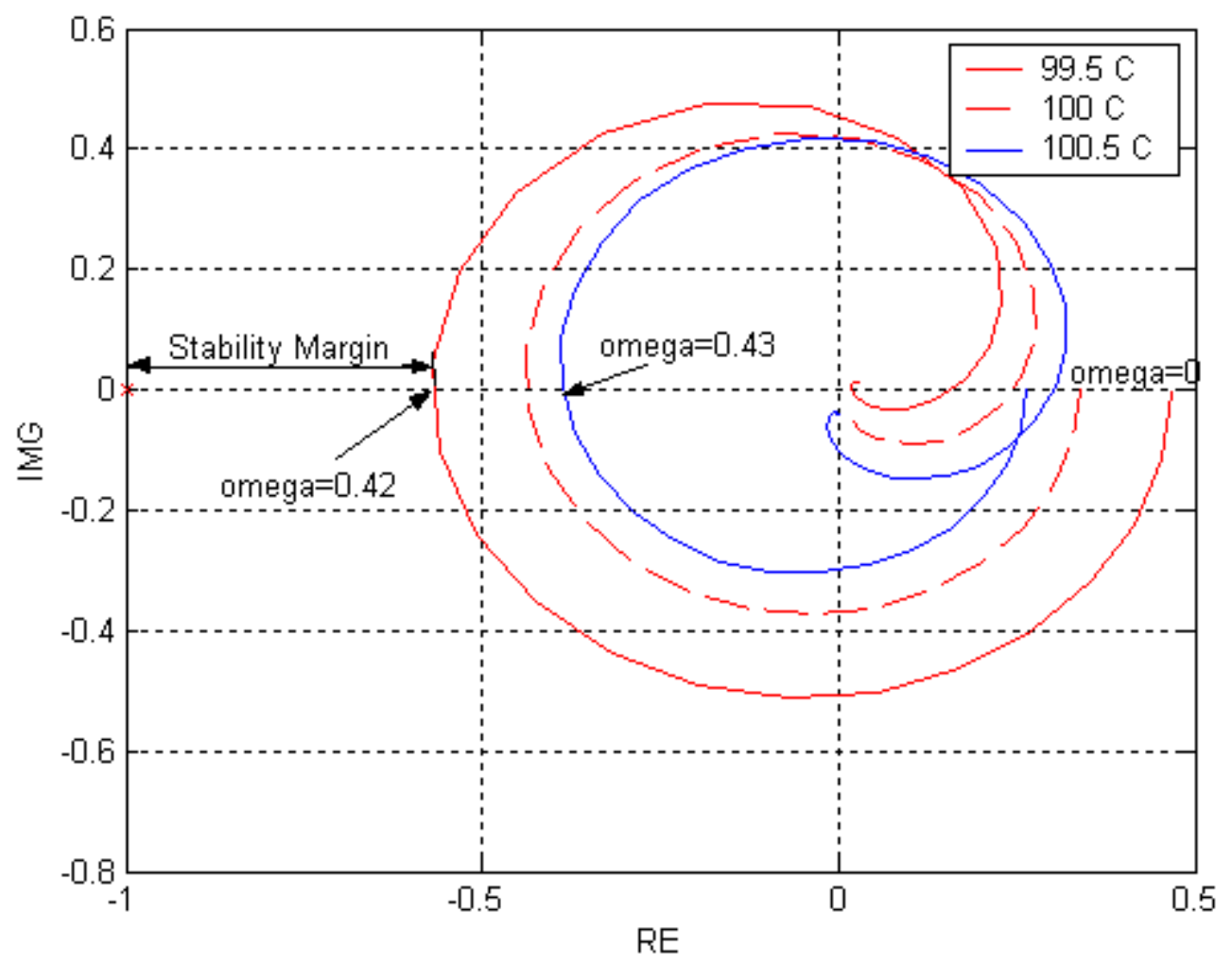

Figure 34. Nyquist Plots for Various Inlet Subcooling 
The Nyquist rule states:

For a closed loop to be stable, the Nyquist plot of its open-loop transfer function must encircle $(-1, j 0)$ as many times as the number of poles of the open-loop transfer function that are in the right hand of the s-plane, and encirclements, if any, must be made in the clockwise direction.

It is obvious from Figure 34 that none of the Nyquist plots for the three cases encircles $(-1, j 0)$. Physically, single-phase region transfer functions $\left(G_{l \varphi}(s)\right)$ and two-phase region transfer function $\left(G_{2 \phi}(s)\right)$ are stable systems. Therefore, the closed-loop function is stable. In other words, no pole is on the right side of the s-plane or the poles and zeros on the right-hand side of the s-plane cancel each other. The following observation could be made about the results shown in Figure 34

1) The system is stable for the three inlet temperature conditions.

2) As core inlet temperature increases, the stability margin increases.

3) The stability margin is sensitive to the core inlet temperature.

Figure 35 shows the Nyquist plots for two different power levels, $11 \mathrm{KW}$ and $12 \mathrm{KW}$. A system pressure of $0.10 \mathrm{MPa}$ and inlet temperature of $99.5^{\circ} \mathrm{C}$ are used in the calcuations. Using the Nyquist rule, the following observations could be made:

1) The closed-loop is a stable system for both power levels

2) The stability margin is improved as power increases.

These initial stability analyses predict stability at higher inlet subcooling than has been achieved on the LPITF, approximately $97^{\circ} \mathrm{C}$. However, the stability analysis reflects the expected trends as a function of power level and inlet subcooling. Work continues to expand the capability and fidelity of the stability analysis into a useful tool for analysis of the LPITF. 


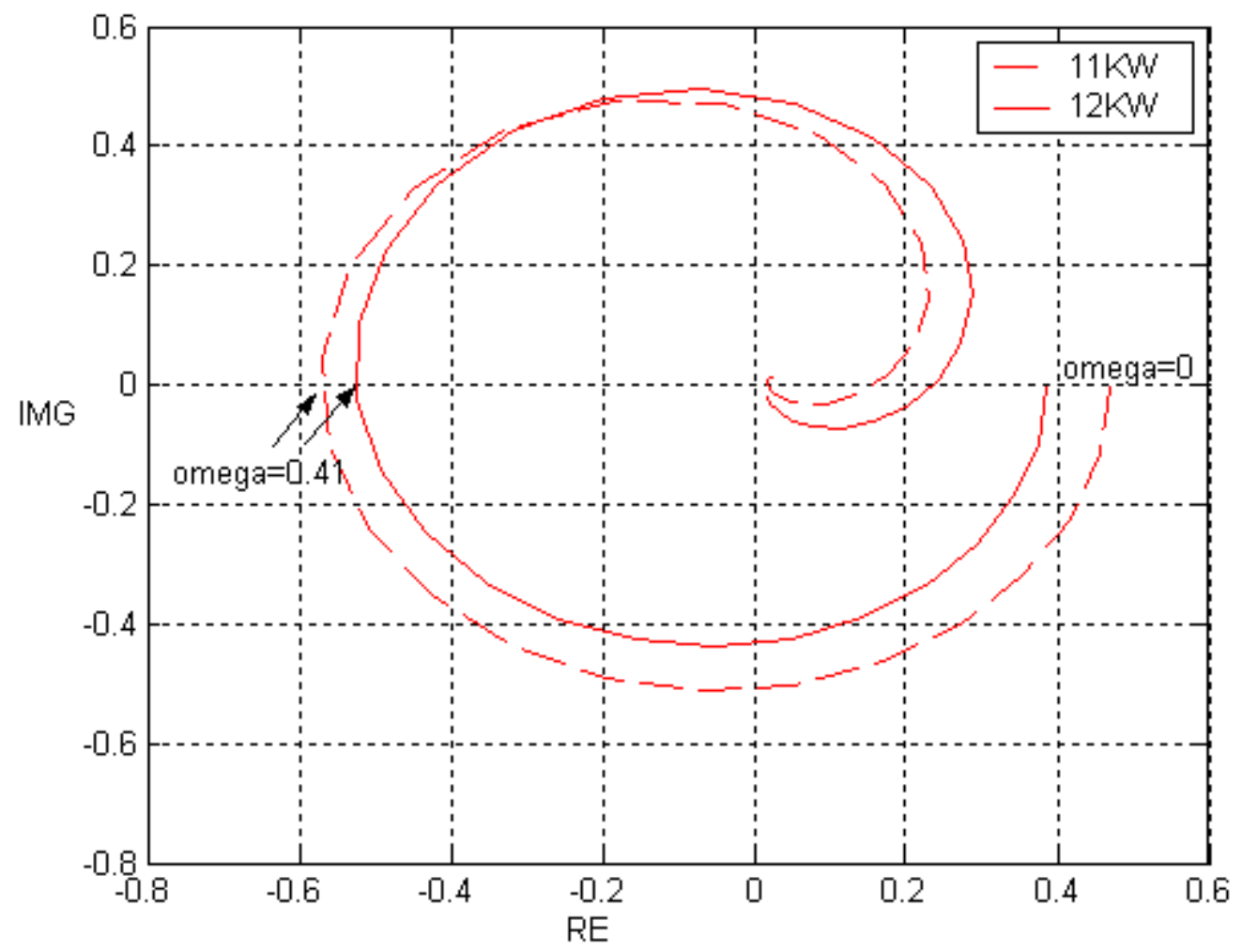

Figure 35. Nyquist Plots for Various Power Levels

\section{CONCLUSION}

The DOE Instrumentation, Controls, and Human Machine Interface (IC\&HMI) Technology workshop was conducted in May 2002 to examine IC\&HMI needs in the design of Nuclear Power 2010 and Generation IV programs. A conclusion identified demonstration facilities as the most important research objective. Research and education for advanced monitoring and control usually fails to take into account real-world characteristics of physical systems, instrumentation and digital implementation. The availability of appropriate experimental facilities and personnel to conduct sophisticated experiments therefore limits the opportunity to develop advanced control techniques to enhance safety and economy in future nuclear power plants.

This NEER project addressed these issues by expanding existing experimental-neutronics advanced-control capability to include experimental capability with a boiling-regime thermalhydraulic test-loop and a coupled neutronics thermal-hydraulic physical system. Research on advanced multi-variable robust control and stability analysis and monitoring was undertaken. 
The benefits of a successful hybrid simulation testbed, with demonstrated capability to validate monitoring and control techniques, could be multiplied in future years to allow remote access to researchers from other institutions via advanced communication capabilities that are now becoming available via internet- 2 . 


\section{REFERENCES}

1. Turso, J.A., R.M. Edwards, and J. March-Leuba, "Hybrid Simulation of Boiling Water Reactor Dynamics Using A University Research Reactor," Nuclear Technology, 110:132-144 (April 1995).

2. Experimental Development Of Power Reactor Intelligent Control; Task IV Hybrid Reactor/Simulation Capability, EPRI RP 8030-04, November 1997.

3. Hughes, D.E., Mac Bryan, and Robert Gould, "Safety Issues Involved in Using the PSBR for Control Algorithm Testing," AI 91: Frontiers in Innovative Computing for the Nuclear Industry, Jackson, Wyoming, (September 15-17, 1991).

4. J. March-Leuba, P.J. Otaduy, "A Comparison of BWR Stability Measurements with Calculations Using the Code Lapur-IV,” NUREG/CR-2998. ORNL/TM-8546, 1983.

5. March-Leuba, J., "Dynamic Behavior of Boiling Water Reactors", A Ph.D. Dissertation in Nuclear Engineering, University of Tennessee, 1984.

6. Todreas, N.E., and M.S. Kazimi, Nuclear Systems I: Thermal Hydraulic Fundamentals, Hemisphere Publishing, 1989.

7. Miguel Cecenas-Falcon, Stability Monitoring for Boiling Water Reactors, Ph.D Thesis, the Penn State University, 1999.

8. Turso, J.A., J. March-Leuba, and R.M. Edwards, "A Modal-Based Reduced-Order Model of BWR Out-of-Phase Instabilities," Annals of Nuclear Energy, 24:921-934, (1997).

9. K. Fukuda, T. Kobori, Classification of Two-Phase Flow Instability by Density Wave Oscillation Model, Journal of Nuclear Science and Technology 16 (2) 1979, 95-108.

10. Aritomi, M., Chiang, J.H., Mori, M. Fundamental study on thermo-hydraulics during startup in natural circulation boiling water reactors (I). J. Nucl. Sci. Technol. 29 (7), 631, 1992.

11. J.H. Chiang, M. Aritomi, R. Inoue, M. Mori, Thermo-hydraulics during startup in Natural Circulation boiling water reactors, Nuclear Engineering and Design 146 (1994) 241-252.

12. F. Inada, M.Furuya, A. Yasuo, Thermo-hydraulic instability of boiling natural circulation loop with a Chimney, Heat Transfer - Japanese Research 24(7), 1995.

13. F. Inada, M.Furuya, A. Yasuo, Thermo-hydraulic instability of boiling natural circulation loop induced by flashing (analytical approach), Nuclear Engineering and Design 200 (2000) 187-199.

14. A. Manera and T.H.J.J van der Hagen, On Stability of Natural-circulation Boiling Water Reactors during Start-up (Experimental Results), ICAPP, Florida, 2002. 
15. A. MANERA, W.J.M. DE KRUIJF, T.H.J.J. VAN DER HAGEN, R.F. MUDDE, Experiments with the CIRCUS-facility on Flashing-induced Instabilities During Startup of Naturalcirculation-cooled BWRs, Proc. PHYSOR 2000, Pittsburgh, Pennsylvania, USA, (2000).

16. LPITF-DSG-497, The Penn State University

17. Wang, S.B., Wu, J.Y., Pan, C., Lin, W.K., Thermal-hydraulic oscillations in a low pressure twophase natural circulation loop at low pressures and high inlet subcool-ings, 4th Int. Topical Meet. Nuclear Thermal Hydraulics, Operations and Safety, Taipei, Taiwan, 1994.

18. Y. F. Rao, K. Fukuda, T. Koga, Experimental and Numerical Study of Two-Phase Flow Instabilities in Natural Circulation Boiling Channels, ICONE5-2105, Nice, France, 1997.

19. J. Paniagua, U.S. Rohatgi, V. Prasad, Modeling of thermal hydraulic instabilities in single heated channel loop during startup transients, Nuclear Engineering and Design 193 (1999) 207-226.

20. S.Y. Jiang, M.S. Yao, J.H. Bo, S.R. Wu, Experimental Simulation Study on Startup of the 5MW Nuclear Heating Reactor, Nuclear Engineering and Design 158 (1995) 111-123.

21. S.Y. Jiang, X.X. Wu, Y.J. Zhang, H.J. Jia, Thermal Hydraulic modeling of a natural circulation loop, Heat and Mass Transfer 37 (2001) 387-395. 


\section{PROJECT BIBLIOGRAPHY FOR DE-FG07-99ID13778}

\section{Theses:}

22. Roman Shaffer, "Design, Simulation, and Validation of Robust Controllers", a Masters Thesis in Nuclear Engineering, The Pennsylvania Stat University, May 2000.

23. Shian-shing Shyu, "A Robust Multivariable Feedforward/Feedback Controller Design for Integrated Power Control of Nuclear Power Plant", A Dissertation in Nuclear Engineering, The Pennsylvania State University, May 2001.

24. Zhengyu Huang, "Fuzzy Logic Controller Design for Overall Control of a Nuclear Power Plant", A Masters Thesis in Electrical Engineering, The Pennsylvania State University, August 2001.

25. Zhengyu Huang, "Fuzzy Adapted Sliding Mode Controller Design for a Nuclear Power Plant", A Dissertation in Nuclear Engineering, The Pennsylvania State University, May 2002.

\section{Publications:}

26. R.M. Edwards. June 2000. Expansion of a Testbed for Advanced Reactor Monitoring and Control. Trans. of the Amer. Nucl. Soc. 82:78-80. San Diego, CA.

27. Ceceñas-Falcón, M., and R.M. Edwards. July 2000. Stability Monitoring Tests Using a NuclearCoupled Boiling Channel. Nuclear Technology. 131:1-11.

28. Ceceñas-Falcón, M., and R.M. Edwards. November 2000. Out-of-Phase BWR Stability Monitoring. Proceedings of The Third American Nuclear Society International Topical Meeting on Nuclear Plant Instrumentation, Control and Human-Machine Interface Technologies, NPIC\&HMIT'2000. 9 pages on CD ROM. Washington, DC

29. Shyu, S., and R.M. Edwards. November 2000. Optimized-Feedforward and Robust-Feedback Used in Integrated Automatic Reactor Control. Proceedings of The Third American Nuclear Society International Topical Meeting on Nuclear Plant Instrumentation, Control and HumanMachine Interface Technologies, NPIC\&HMIT'2000. 8 pages on CD ROM. Washington, DC.

30. He, W., Z. Huang, and R.M. Edwards. November 2000. Experimental Validation of OptimizedFeedforward Control for Nuclear Reactors. Proceedings of The Third American Nuclear Society International Topical Meeting on Nuclear Plant Instrumentation, Control and Human-Machine Interface Technologies, NPIC\&HMIT'2000. 8 pages on CD ROM. Washington, DC.

31. Huang, Z., and R.M. Edwards. November 2000. Hybrid Reactor Simulation of BWR Using a First Principle Boiling Channel Model. Proceedings of The Third American Nuclear Society International Topical Meeting on Nuclear Plant Instrumentation, Control and Human-Machine Interface Technologies, NPIC\&HMIT'2000. 8 pages on CD ROM. Washington, DC.

32. Shaffer, R., W. He, and R.M. Edwards. November 2000. Experimental Validation of Robust Control for Nuclear Reactors. Proceedings of The Third American Nuclear Society International Topical Meeting on Nuclear Plant Instrumentation, Control and Human-Machine Interface Technologies, NPIC\&HMIT'2000. 9 pages on CD ROM. Washington, DC. 
33. Edwards, R.M., Z. Huang, and W. He. November 2000. Integration of a Thermal-Hydraulic Testloop and University Research Reactor for Advanced Monitoring and Control Research. Proceedings of The Third American Nuclear Society International Topical Meeting on Nuclear Plant Instrumentation, Control and Human-Machine Interface Technologies, NPIC\&HMIT'2000. 8 pages on CD ROM. Washington, DC.

34. Huang, Z., and R.M. Edwards. 2000. BWR Hybrid Reactor Simulation Using an Experimental Changeable Reactivity Device. Trans. of the Amer. Nucl. Soc. Student Conference. Raleigh, NC. 1 page.

35. Shaffer, R.A., and R.M. Edwards. 2000. Robust Reactor Control for Autonomous Systems. Trans. of the Amer. Nucl. Soc. 82:75-76. San Diego, CA.

36. R.M. Edwards. 2000. Expansion of a Testbed for Advanced Reactor Monitoring and Control. Trans. of the Amer. Nucl. Soc. 82:78-80. San Diego, CA.

37. Huang, Z., and R.M. Edwards. 2001. Simulation of BWR Out-of-Phase Oscillation Using a University Research Reactor. Trans. of the Amer. Nucl. Soc. Student Conference. College Station, TX. 7 pages on CD ROM.

38. He, W., and R.M. Edwards. 2001. Robust Design an Evaluation of On-line Uncertainty Monitoring System on a Reactor. Trans. of the Amer. Nucl. Soc. Student Conference. College Station, TX. 6 pages on CD ROM.

39. Cetiner, M., and R.M. Edwards. 2001. The Pennsylvania State University Low Pressure Integral Test Facility Data Acquisition System and User Interface. Trans. of the Amer. Nucl. Soc. Student Conference. College Station, TX. 7 pages on CD ROM.

40. Huang, Z., and R.M. Edwards. 2001. Hybrid Reactor Simulation and 3-D Information Display of BWR Out-of-Phase Oscillation. Trans. of the Amer. Nucl. Soc. 84:99-100. Milwaukee, WI.

41. He, W., and R.M. Edwards. 2001. Evaluation of a Reactor On-Line Uncertainty Monitoring System. Trans. of the Amer. Nucl. Soc. 84:111-112. Milwaukee, WI.

42. Cetiner, S.M., L.E. Hochreiter, R.M. Edwards, W. He, and Z. Huang. 2001. Two-Phase Natural Circulation Experiments in The Penn State Low-Pressure Integral Test Facility. Trans. of the Amer. Nucl. Soc. 85:311-333. Reno, NV.

43. Ceceñas-Falcón, M., and R.M. Edwards. 2001. Application of a Reduced Order Model to BWR Corewide Stability Analysis. Annals of Nuclear Energy. 28:1219-1235.

44. Huang, Z., and R.M. Edwards. 2002. ABWR Plant Overall Control Using Fuzzy Logic Control Technique. Trans. of the Amer. Nucl. Soc. 86:180-182. Hollywood, FL. (First author supervised by candidate) 
45. Cetiner, S.M., and R.M. Edwards. Integration of a Thermal-Hydraulic Test Loop and University Research Reactor For Advanced Control. 2002. Trans. of the Amer. Nucl. Soc. 86:195-196. Hollywood, FL. (First author supervised by candidate)

46. He, W., and R.M. Edwards. 2002. Evaluation of in-phase BWR Stability Monitor with a Hybrid Reactor Facility. Trans. of the Amer. Nucl. Soc. 86:242-243. Hollywood, FL. (First author supervised by candidate)

47. He, W., Z. Huang, and R.M. Edwards. 2002. Advanced BWR Stability Monitoring Tests with a Hybrid Reactor Facility. Proceedings of American Nuclear Society Topical Meeting, International Congress on Advanced Nuclear Power Plants (ICAPP), 6 pages on CD ROM. (First author supervised by candidate)

48. Huang, Z., and R.M. Edwards. 2002. Sliding Mode Control Application in ABWR Plant Pressure Regulation. Proceedings of American Nuclear Society Topical Meeting, International Congress on Advanced Nuclear Power Plants (ICAPP), June 2002. 8 pages on CD ROM.

49. Cetiner, S.M., and R.M. Edwards. 2002. Results of Coupling a Thermal-Hydraulic Test Loop and University Research Reactor. Proceedings of American Nuclear Society Topical Meeting, International Congress on Advanced Nuclear Power Plants (ICAPP). 7 pages on CD ROM.

50. Huang, Z., K.Y. Lee, and R.M. Edwards. 2002. Fuzzy Logic Control for Nuclear Power Plant Overall Control. Proceedings of 15th IFAC World Congress. Barcelona, Spain. 6 pages on CD ROM.

51. Shyu, S., and R.M. Edwards. 2002. A Robust Multivariable Feedforward/Feedback Controller Design for an Integrated Power Control of Boiling Water Reactor Power Plants. Nuclear Technology. 140:129-146.

52. Ceceñas-Falcón, M., and R.M. Edwards. 2003. Out-of-Phase BWR Stability Monitoring. Nuclear Technology. 143: 125-131.

53. Huang, Z., and R.M. Edwards. 2003. Hybrid Reactor Simulation of BWR Power Oscillations. Nuclear Technology. 143:132-143.

\section{Manuscripts accepted:}

54. Shaffer, R., W. He, and R.M. Edwards. Design And Validation Of Optimized Feedforward With Robust Feedback Control of A Nuclear Reactor. Submitted December 2001 for publication in Nuclear Technology.

\section{Manuscripts submitted:}

55. Huang, Z., R.M. Edwards, and K.Y. Lee. Fuzzy Adapted Recursive Sliding Mode Controller Design for a Nuclear Power Plant Overall Contol. Submitted August 2003 to IEEE Transactions on Control Systems Technology. 


\section{APPENDIX}

\section{Testloop Safety Review}

The 3-inch borosilicate glass chimney of the LPITF failed on April 19, 2002. A committee met on May 7, 2002 to review LPITF Safety and recommended the following modifications.

- It was proposed that the failed section, and downcomer lines be modified as shown in Figure A-1, which includes the following new features:

- The chimney that replaces the failed glass section (including the glass $T$ to the crossover leg) is copper piping and includes two hose sections to isolate vibration and transmission of periodic stresses to the remaining 3-inch glass section.

- The crossover leg and a substantial portion of the downcomer are replaced with 3-inch copper to provide a larger inventory of saturated water for recirculation. (Steady state analysis of two-phase natural circulation suggests that steady-state flow rates may be extremely sensitive to downcomer level. The increased saturated water volume is expected to help reduce downcomer level fluctuations and thus improve the stability characteristics of the system.)

- The separator drain and condensate return lines are rearranged to join the recirculation path well below the liquid level. This arrangement ensures that it is not possible for significant vapor to follow a reverse path to the condenser. This arrangement is viewed as providing gravity-assisted condensate pumping and separator drain pumping.

- The separator drain and condensate return lines each contain short glass sections (about four feet and isolated with rubber hose connections) of 1.5 inch glass to allow the observation of liquid inventory and downcomer level fluctuations. These glass sections are the only glass in the return line to the bundle.

- The location of hose connections allows most of the copper components to be bench soldered.

- Silicon rubber-hose material that is used in the facility has a temperature rating of 350 ${ }^{\circ} \mathrm{F}$ and pressure rating of $58 \mathrm{psig}$ (for 3.25 inch hose).

- The LPITF Operating Procedures have been updated. 


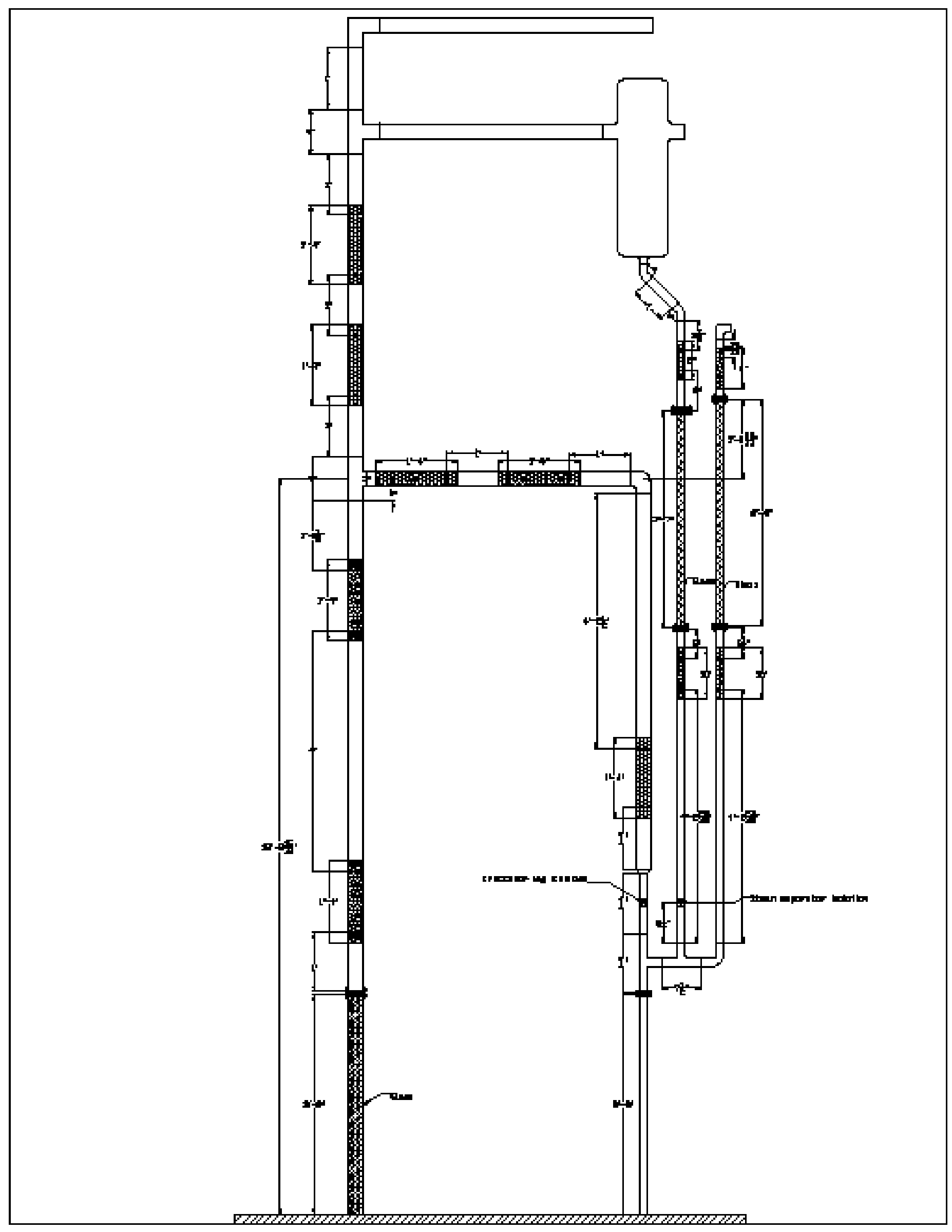

Figure A-1. Modified LPITF 